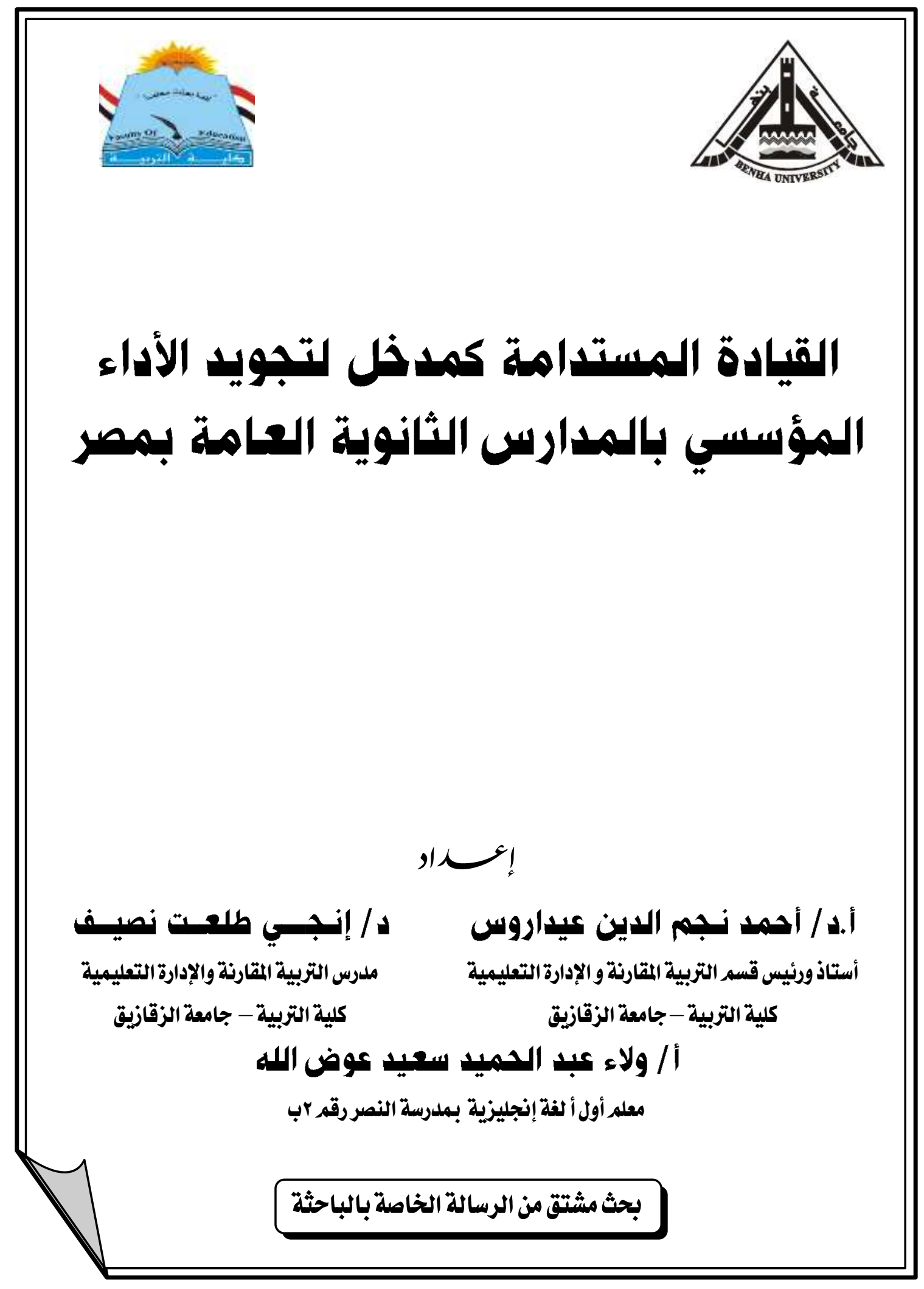




\section{القيادة المستدامة كمدخل لتجويد الأداء المؤسسي بالمدارس الثانوية العامة بمصر}<smiles>[AlH2]C[AlH2]</smiles>

د/ إنبي طلعـات نصدف:

مدرس التربية المقارنة والإدارة التعليمية

كلية التربية - جامعة الزقازيق
أ.د/ أحمد نجيم الدين عيداروس

أستاذورئيس قسم التربية المقارنة و الإدارة التعليمية كلية التربية - جامعة الزقازيق

\section{أ / ولاء كبد الحميد سعيد كوض اللهابه}

معلم أول أ لفة إنجليزية بمدرسة النصر رقم بب

\section{مستخلص}

هـف البحـث الحـالي إلىى التعـرف على الاطــار النظـري الـي يحكم تجويــ الأداء

المؤسسي مثل ماهيـة الأداء المؤسسي ومقومـات الاداء المؤسسي، والتعرف على الاطـار النظري الذي يحكم مدخل القيادة المستدامة ومفهومها ومبادئها ودور مدخل القيادة المستدامة في تجويد الأداء المؤسسي بالمدارس الثانوية العامة بمصر ، طرح مجموعة من المقترحات التي تسـهم في تجويـد الأداء المؤسسـي بالمـارس الثانويـة العامـة بمصـر مـن خـلال مـدخل القيـادة المستدامة، استخدم البحث المنهج الوصفي، وأظهر البحث أن تجويد الأداء المؤسسي جزء لا يتجزأ من العملية التعليمية، وأن القيادة المستدامة تهدف إلى تحسين العملية التعليمية والتربويـة وتجويد الأداء المؤسسي بالمدارس الثانويـة العامـة وذلك عن طريق توعيـة العـاملين بالمدرسـة بواجباتهم والعمل على تحقيق أهداف المدرسة. 


\section{Ahstract}

The objective of the current research is to identify the theoretical framework that governs the improvement of institutional performance such as what is the institutional performance and the elements of institutional performance. And to identify the theoretical framework that governs the entrance of the sustainable leadership and its concept and principles and the role of the introduction of sustainable leadership in improving the institutional performance in public secondary schools in Egypt. A number of proposals have been put forward that contribute to improving the institutional performance of the public secondary schools in Egypt through sustainable leadership. The research Used the descriptive method. The research showed that the improvement of institutional performance is an integral part of the educational process And that sustainable leadership aims to improve the educational and educational process and improve institutional performance in secondary schools, By educating school staff about their duties and working towards achieving the school's goals. 
يثـهـ العـالم في الآونـة الأخيرة الكثير مـن المتغيرات السريعة والمتلاحقـة في شتي

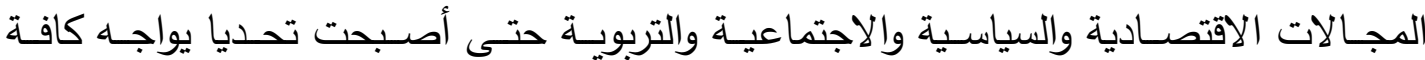
الهجتعـات ، والذي انعكس بدوره على الاهتمام بمدى فاعليـة المؤسسـات التعليميـة وتأديـة وظائفها وتحقيق الأهداف التي انشئت من أجلها سواء كانت هذه المؤسسات ، في ضوء العديد من المستجدات والظروف التي أصبحت ترهق كاهل المسئولين في هذه المؤسسات.

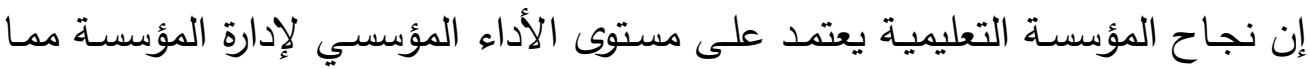
يؤدي إلى تحقيق أهدافها بكفاءة وفاعلية والوصسول إلى الميزة التتافسية ، والمدرسـة الثانويـة العامة من بين المؤسسات التعليمية التي تحتل مكانة هامة بين المؤسسات التعليمية ، حيث أنها تعد الطالب لمواصلة دراسته في المرحلة الجامعية وإكسابه العديد من المهارات اللازمـة لمواجهة التحديات الجديدة ، ويعد تجويد الأداء المؤسسي هو أحد متطلبات العملية التعليمية التي لا يمكن تجاهلها أو إغفالها. وينعكس النمط القيادي المتبع على مستوى المدرسـة الثانويـة العامـة ، وعلى الأداء

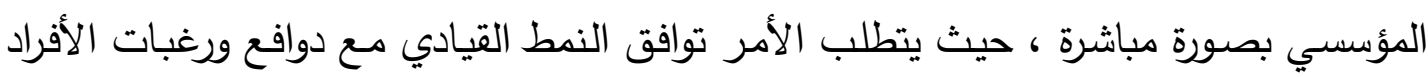

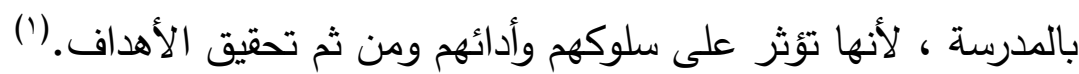

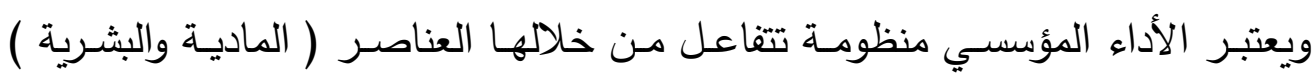

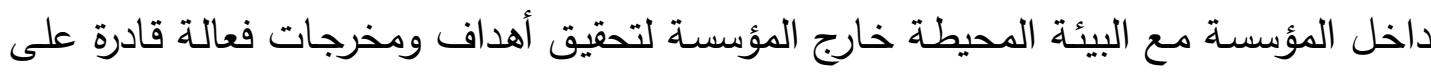
التنافس في ظل عصر المعلوماتية ، ذلك العصر الذي يتطلب من المؤسسات ضرورة أن تكون لـونه

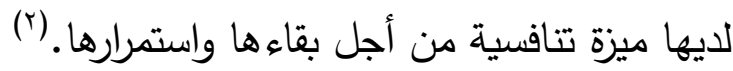

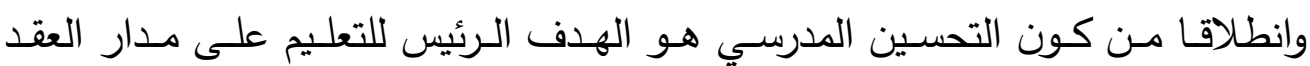

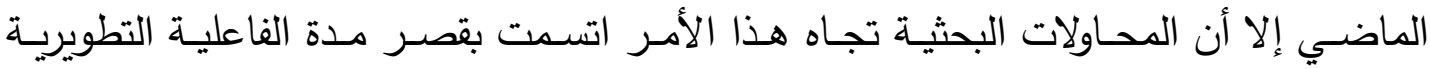

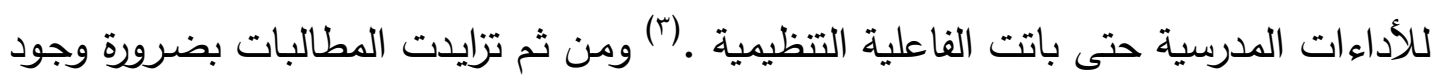
استراتيجيات مستدامة للتحسين المدرسي بما يتواكب ومستحدثات وتقنيات التطورات الأكاديمية والإدارية والمجتمعية. (£) 
ومن الجدير بالذكر أن استدامة التطوير المهني لكافة الفعاليات والأنشطة المدرسية هي حجر الأسـاس للتحسين والتطوير المدرسي.(0)وهذا يبرهن على كون القيادة المستدامة نمطا قياديا متكاملا لقيادة المؤسسات التعليمية ، إذ أنها تولي اهتماما متوازنا بالجوانب الأيكولوجية(؟)

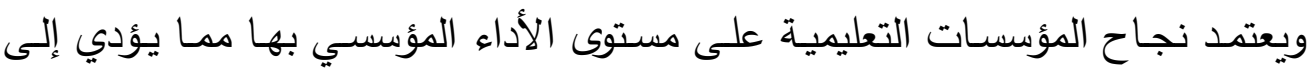
تحقيق أهدافها بكفاءة وفاعلية بشكل ينعكس على مستوى جودة مخرجاتها ونتاجها ، وكون القيادة المستدامة تركز على التحسين المستمر داخل المدرسـة لذلك فهي تعد النمط القيادي المناسب الذي يساعد في تجويد الأداء المؤسسي.

وبالرغم من الجهود المبذولة لتطوير إدارة المدرسة الثانويـة العامة ومنها أن ضمن أحد الأهداف الاستراتيجية لبرنـامج التعليم الثانوي في الخطـة الاستراتيجية للتعليم قبـل الجـامعي

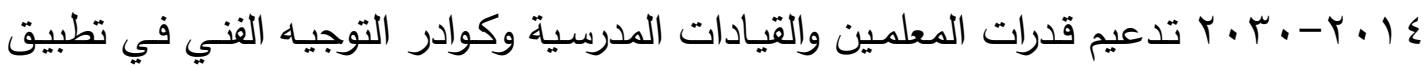
منظومة تحديث التعليم الثانوي (У)وأيضاً ضمن الأهداف الاجرائية التي وضعتها الهيئة القومية لضــمان جـودة التعليم والاعتمـاد أن تعمـل المؤسسـة على تحسـين وتطـوير أسـاليب القيـادة المؤسسـية وتطـوير أسـاليب الأداء ، والتقـويم المؤسسـي والتعليمسي (^) ،إلا أن واقـع المدرســة الثانوية العامة - من خلال الدراسات والبحوث - يشير إلى وجود العديد من المشكلات وأوجه القصور، وتتمثل في نقص البرامج التدريبية التي توجه للمديرين ، وغياب الأسـاليب الإداريـة الحديثة، وضعف قنوات الاتصال بين أفراد المجتمع المدرسي، والفردية في اتخاذ القرارات وقلة

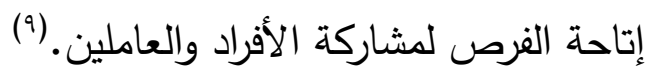
وباستقراء الخطة الاستراتيجية للتعليم قبل الجامعي ع ا ـ r| • • ـ فقد أبرزت العديد من المشكلات في التعليم الثانوي العام ومنها ما يلي: • أن التعليم الثانوي العام يعاني من عزوف الطلاب عن الحضور بالمدرسة مما يؤدي بصفة مباشرة إلى إهدار المال العام والذي يتمثل في عدم استغلال المباني المدرسية وكذلك زيادة الدروس الخصوصية ، وذلك له صلة مباشرة بمدى جودة الإدارة المدرسية.(·') مما يؤكد على ضـرورة إيجـاد نمط قيادي متكامل لمواجهة هذه المشكلات ومحاولة القضـاء عليها والنهوض بمستوى التعليم الثانوي العام. والمتأمل لواقع إدارة المدرسة الثانوية العامة بجمهورية مصر العربية ، يجد أنها تعاني من قصور في الأبعاد التالية : 


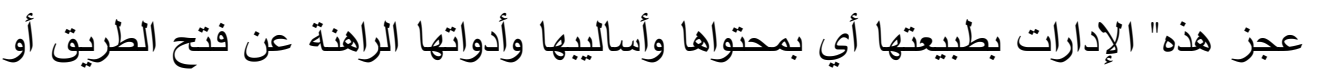

التمهيد للتطورات التعليمية المنظرة و المطلوبة خلال السنوات القادمة.(') • كثرة الأعباء والمسئوليات التي يواجهها المديرين.

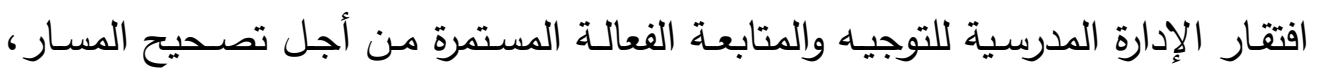

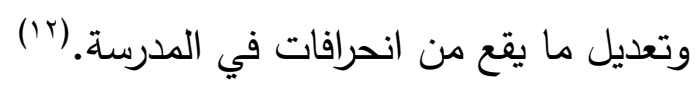

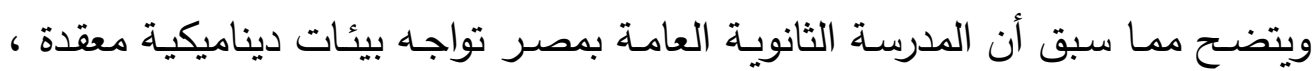

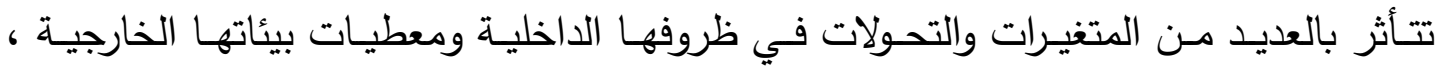
ويتطلب ذلك من هذه المؤسسات العمل على تحسين مستوى أداءها باستمرار ، وتطوير قدراتها

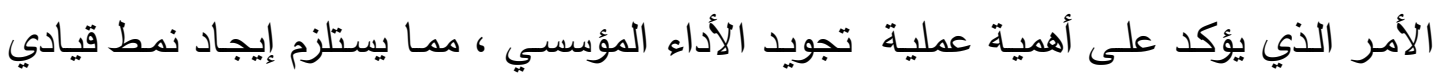

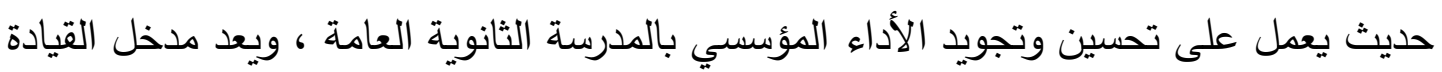
المستدامة من أفضل المداخل الادارية المناسبة لتجويد الأداء الإداري. وفي ضوء ما سبق يمكن بلورة مشكلة البحث في الأسئلة التالية :

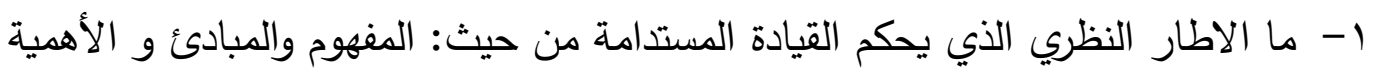

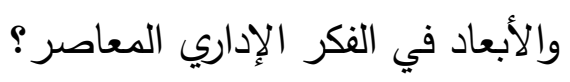

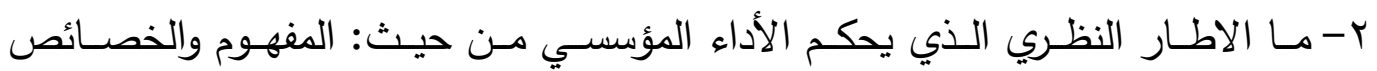

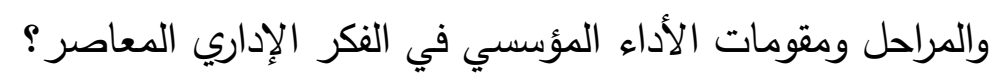

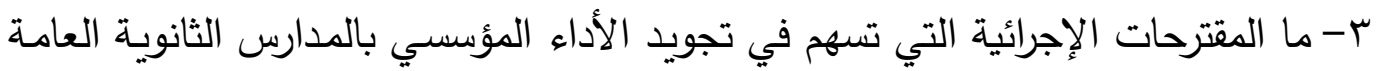
بمصر من خلال مدخل القيادة المستدامة ؟

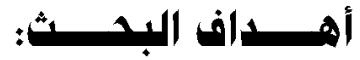

\section{يسعى البحث الراهن لتحقيق الأهداف التالية:}

التعرف على الإطـار النظري الذي يحكم للقيادة المستدامة من حيث :المفهوم والمبادئ

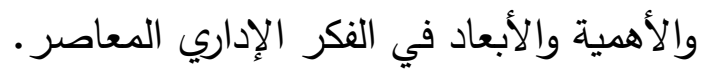

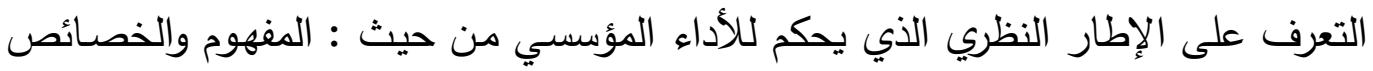

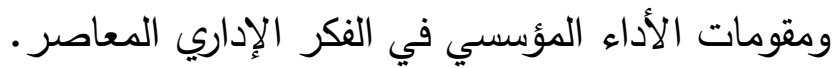

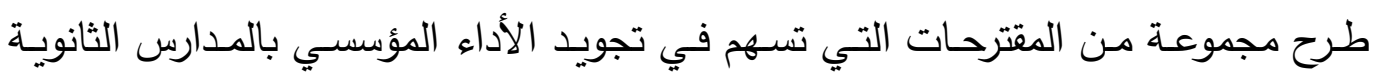
العامة بمصر في ضوء مدخل القيادة المستدامة. 


\section{تتمثل أهمية البحث الحالي فيما يلي:}

الأهمية النظرية والمتمثلة في البحث الحالي بالوصف والتحليل لمتغيري البحث وهما القيادة المستدامة والأداء المؤسسي وهما من المتغيرات الحديثة في مجال الإدارة التربويـة، وتبرز الأهمية من الاثراء الذي قد تسهم فيه من خلال تتبع الأدب النظري والدراسات السابقة لمتغيري الدراسة بالثكل الذي يكون إطاراً مفاهيمياً متكاملاً عن المتغيرات ومنهجية دراستها. الأهمية التطبيقية والمتمثلة في تجويد الأداء المؤسسي بالمدرسة الثانويـة العامـة بصصر في ضـوء مدخل القيادة المستدامة مما يحقق أعلى معدلات الإنجاز المؤسسي المستدام من خلال التوصل لمجموعة من المقترحات التي تسهم في تجويد الأداء المؤسسي.

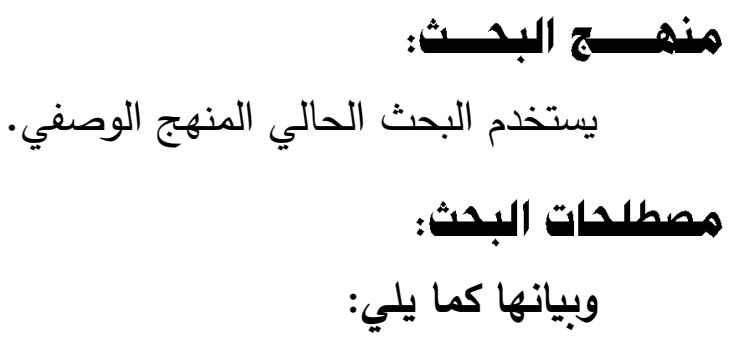

Sustainable leadership : القيادة المستلامة

هي خلق ثقافة الانجاز المستمر ، وهي قدرة المدارس والأفراد على الاستمرار لمواجهة التحديات الجديدة والمعقدة بطريقـة لا تضـر بالأفراد أو المجتمع، وبناء قدرات الأفراد للانتقال بالمدرسـة من الوضـع الحـالي إلى المطلوب والاستمرار في التحسين لمواجهة المستقبل وبنـاء

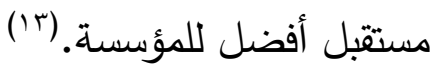
كمـا تعـرف علـى أنهــا المسئولية المشـتركة ،وأنهــا لا تســتخدم المــوارد البثــرية

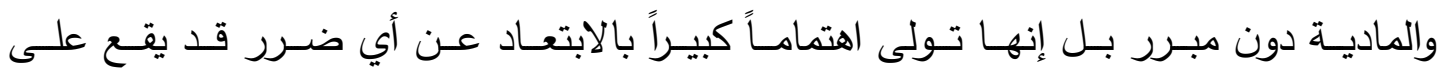

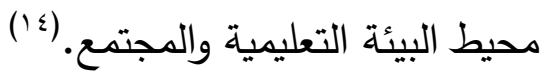

\section{التنعريف الإجرائي لاقبيادة المستندامة :}

ويمكن تعريف القيادة المستدامة إجرائياً : بأنها النمط القيادي الداعم آليات الاستدامة الفاعلة من أجل مستقبل أفضل من خلال الرؤى الاستراتيجية والتفكير المنظمي وآليات التفاعل الايجابي بما يؤدي لتجويد الأداء المؤسسي بالمدارس الثانوية العامة . 


\section{الأداء المؤسسي : Institutional performance}

يعرف الأداء المؤسسي على أنه سلوك أو جهد مبذول لتحقيق الأهداف المطلوبـة ،

ويؤدي إلى نتيجة في البيئة والمجتمع (10)

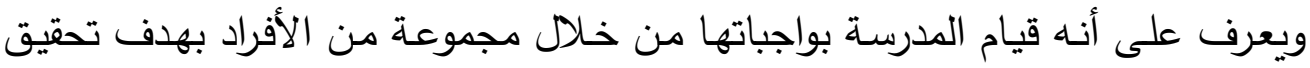

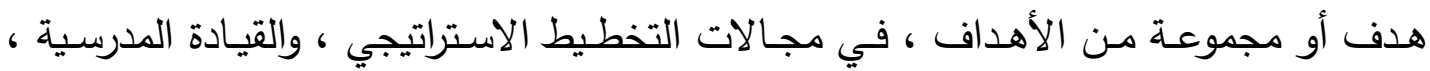

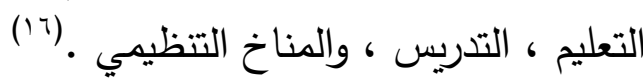

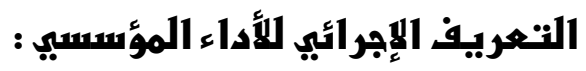

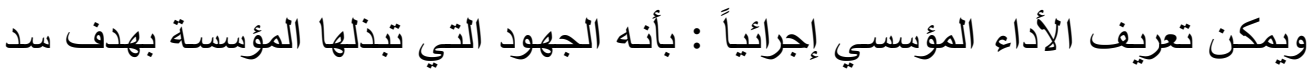

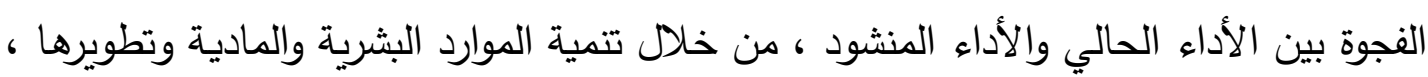

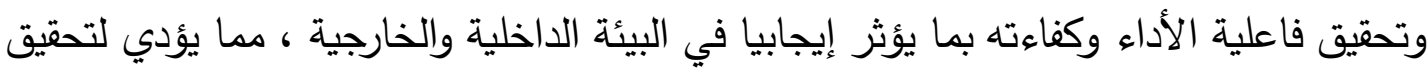
التميز وبالتالي تحقيق الأهداف المرغوبة للمؤسسة.

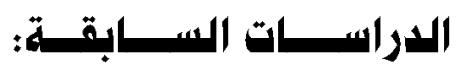

يتم عرض الدراسات السابقة من الأحلث إلى الأقدم كما يلي:

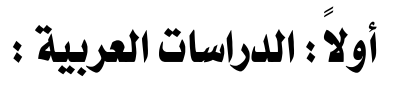

1- تطوير الأداء المؤسسي بالمدرسية سة الثانوية العامة في مصر في ضوء مدخل القياسر

المرجهي (iv)

هدفت الدراسـة إلى :الكثف عن الأسس النظريـة للـأداء المؤسسي بالمدارس الثانويـة

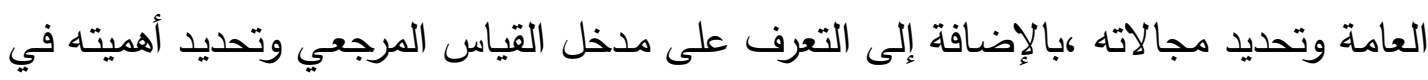

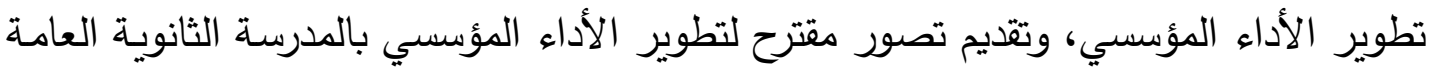

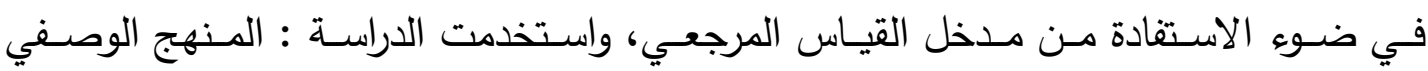

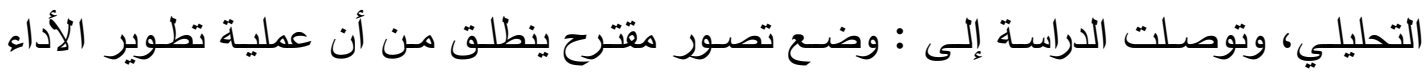
المؤسسي بالمدرسة الثانوية العامة مستمرة ومرتبطة بالعاملين، وتعتمد بشكل أساسي على نقئ نتائج عملية تقييم الأداء.

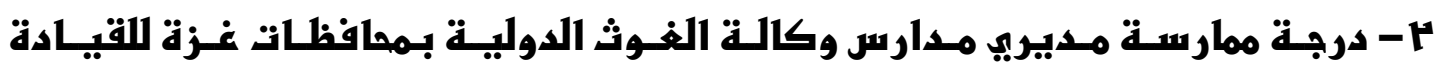
المستنامة و علاقتما بجودة الهياة الوظيفية لدى معلميهم (1N) هدفت الدراسة إلى : قياس درجة ممارسة مديري مدارس وكالـة الغوث الدوليـة للقيادة المستدامة بمحافظات غزة ، الكثف عن دلالات الفروق في تقديرات أفراد العينة لدرجة ممارسة داته 
مديري مدارس وكالة الغوث الدولية للقيادة المستدامة تبعا ل لمتغيرات الدراسـة من وجهة نظر معلميهم ، الكثف عما إذا كانت هناك علاقة ارتباطية بين درجة ممارسة مديري مدارس وكالة الغوث الدولية بمحافظات غزة للقيادة المستدامة وبين جودة الحياة الوظيفيـة لدى معلميهم ، استخدمت الدراسـة : المنهج الوصفي، توصلت الدراسـة إلى مجموعـة من النتائج منها: عدم وجود فروق ذات دلالة إحصائية عند مستوى دلالة ( 0 . a a) بين متوسطات درجات تقدير أفراد عينـة الدراسة لدرجة ممارسـة مديري مدارس وكالة الغوث الدولية بمحافظـات غزة للقيادة المستدامة ، وجود فروق بين كل من الذين يعملون في مدارس الذكور ومدارس الإناث ولصالح الذين يعملون في مدارس الذكور •

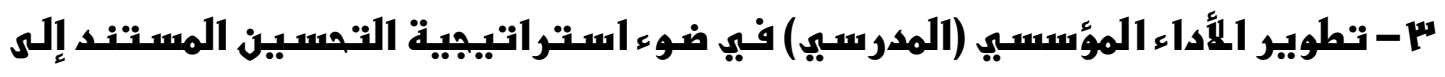

المدربسة "مهارسر الظفهران دراستة حالة (19)

هدفت الدراسـة إلى : توضـيح الأسس النظريـة لتطـوير الأداء المؤسسي مثل مفهوم تطوير الأداء المؤسسي ، جواني تقييم الأداء المؤسسي ودراسـة أهم تجارب الدول العربية في الهي مجال تطوير الأداء المدرسي مثل مشروع تمام ، ومناقشّة خصـائص البحث الاجرائي وأنواعـا ودوره في تطوير الأداء المدرسي ، ومعرفة مظاهر تطوير الأداء المؤسسي والمظاهر التجديدية التربويـة في مدارس الظهران الأهلية ، استخدمت الدراسة : المنهج الوصفي والمنهج التكاملي، وتوصلت الدراسة لمجموعة من النتائج منها: أن عملية تطوير الأداء المدرسي هي جزء لا يتجزأ من العملية التربويـة ،ومشروع تمـام هو مشروع تجديدي تربوي قائم على فكرة تطوير الأداء المؤسسي المستتد إلي المدرسة.

ع- تطوبر الأداء المؤسسسي بـمدار سلر التهليم النّانوي العام بدولة الكوبـت فني ضوء

مدخل الادارة بـالمشناركة

هدفت الدراسـة إلى : التعرف على الاطـر النظريـة لـلأداء المؤسسي، والوقوف على الاسـس النظريـة لمـدخل الادارة بالمشـاركة في ضـوء الفكر الاداري المعاصـر، والتوصـل إلى استراتيجية مقترحة لتطوير الأداء المؤسسي بمدارس التعليم الثانوي العام في دولة الكويت في ضـوء مــدخل الإدارة بالمشـاركة، اسـتخدمت الدراســة : المـنهج الوصـفي، وتوصـــت الدراســة لمجموعة من النتائج منها : تدني قناعة المعلمين بأهمية المشاركة في الإدارة، ومقاومة التغيير لدى المعلمين، وضعف عملية الاتصال الاداري التي يمكن أن تعيق تطبيق الاستراتيجية. 
0- درجة فا علية مشرو ع التطوير التربوي (ERFKE) في تطوير الاداء المؤسسي نهو

الاقتصاد المعر في في مدارسر محافظة جرش من وجمة نظر المديرين (FI)

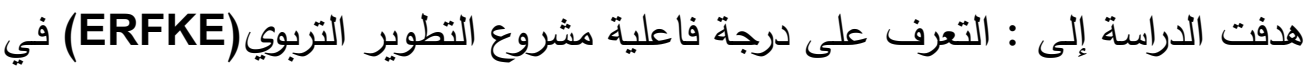

تطوير الاداء في مدارس محافظة جرش من وجهة نظر الدديرين ، استخدمت الدراسة : المنهج

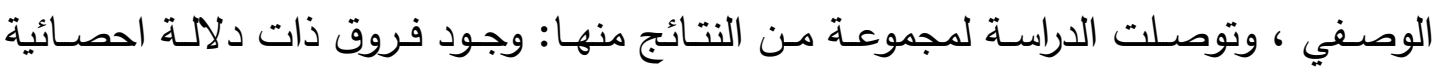

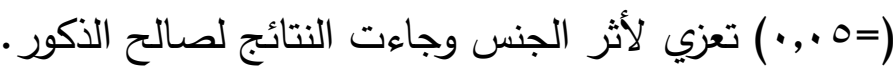

1- تطوير الاداء المؤسسي لإدارات التربية والتعليم بالمهلكة العربيـة السعهودية :

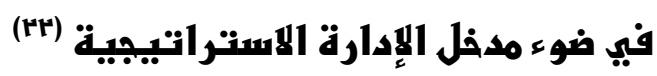

هدفت الدراسة إلى: الكثف عن الأسس النظرية للإدارة الاستراتيجية ومتطلباتها لتطوير

الأداء المؤسسي، والتعرف على الواقع الحالي لجهود تطوير الاداء المؤسسي لإدارات التربية

والتعليم بالمملكة العربية السعودية على المستويين النظري والميداني، استخدمت الدراسة: المنهج الوصفي، توصلت الدراسـة إلى عدة نتائج منهـا: التوصل لتصـور مقترح مـن خـلال التتبؤ بالتطورات المستقبلية بعد أخذ رأي مجموعة من خبراء الإدارة التربوية والتخطيط التربوي حول موضوع الدراسة، وذلك من أجل التوصل إلى تصور مقترح لتطوير الأداء المؤسسي بإدارات التربية والتعليم بالمملكة العربية السعودية في ضوء مدخل الإدارة الاستراتيجية. V- القيادة المستدامة ودورها في إرساء ثقافة النزاهة التنظيمية بمؤسسات التعليم العام بالمملكة العربية السعودية (rF)

هدفت الدراسة إلى : التعرف على كينونة القيادة المستدامة والنزاهة التتظيمية من حيث المفهوم والآليات وتحديات التطبيق والمؤشرات ، وتوضيح دور القيادة المستدامة في إرساء ثقافة النزاهـة التنظيميـة بمؤسســات التعليم العـام بالمملكـة العربيـة السـعودية، واسـتخدمت الدراســة :المنهج الوصفي، وتوصلت الدراسـة إلى مجموعـة من النتائج منهـا: توطين نمطية القيادة المستدامة وإرساء ثقافة النزاهـة التظظيمية بمؤسسات التعليم العام بالمملكة العربية السعودية، استخدام المنهجية البحثية لتحسين الممارسات والتعلم المستدام ، واستـامة التحديث والتطوير لكافة أبعاد التعليم والتعليم المهني. 


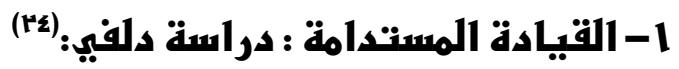

هدفت الدراسـة إلى : استكثــاف آراء الخبـراء المـدربين للقيـادة فيمـا يتعلق بالمهارات الحالية والمعرفـة وأنشطة القـادة المستدامين الحالية ، وتوقع الاتجاه المستقبلي المحتمل للقادة المستدامين للمساعدة في بناء برامج التدريب للقادة المستدامين الناجحين ، واستخدمت الدراسـة : اسلوب البحث المختلط المعتدل لدلفي ، وتوصلت الدراسة إلى: أن القادة المستدامين الحاليين يركزون على أصحاب المصلحة الداخليين والخـارجيين ، بما في ذلك مفاهيم التعاون والتنوع والعمل الجمـاعي ، بـدلا مـن تحقيق التوازن بـين الركائز الأربـع للقيـادة المستـامة ، واعتبـار التكنولوجيـا والتنميـة الثخصـية محــورا للقيـادة المسـتـامة في المسـتقبل وفقـا لفريـق خبـراء هذه الدراسة.

(Fo): ثائد التبديب الذاتي : اتمال العقل والروح والهسب الكامن في القيادة المستندامة تعتمــــــه الدراسـة على أبحـاث الارهـاق والاجهـاد على قـادة المــارس مـن خـلال استكثـاف الممارسـات الشخصـية والمعتقدات المتعلقـة بالرفـاه وتجديد الذات للمدراء الذين تم تحديديهح على أنهم ناجحون، واستخدمت الدراسة: المنهج الوصفي، كثفت نتائج الدراسة عن: التحديات الحالية في التجديد الثخصي والمهني لمديري المدارس، وشملت النجاحات الشخصية الانتباه الى النظام الغذائي والوقت الذي يقضيه المدير مـع العائلة والاصدقاء وممارسـة الرياضـة، وكان النجاح المشترك لمديري المدارس هو استخدام التصرف الايجابي في مواجهة ضغوط العمل.

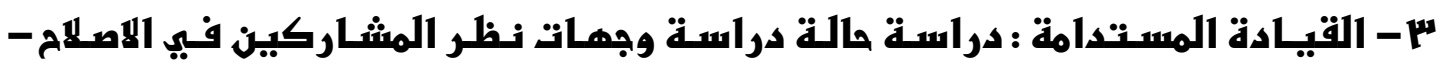
طويل الأمد: (r1) هدفت الدراسة الحالية إلى: البناء على عمل هارجريفز وفينك ؟ . . ب لتحديد المزيد من الامثلـة للقيـادة المسـدامة في سـياق الاصـلاح التعليمي، واسـتخدمت الدراسـة: دراسـة الحالـة، وتوصلت الدراسة إلى مجموعة من النتائج منها: أن القيادة المستدامة واضحة لدى القادة، وأن القادة يمكنه الانتقاص من الاستدامة عندما يكون فهم عنصر الاصـلاح سطحي، وعند شعور الناس بالتهايد، وأن تصرفات قادة الاصلاح يمكن أن تؤثر على كيفية تصور المشاركين القادة أنفهه . 
(Fv): تأثير إدارة الموارد البشرية الاستراتيبية على الأداء المؤسسيس

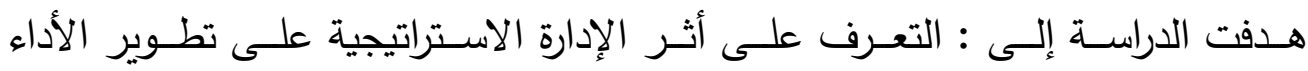

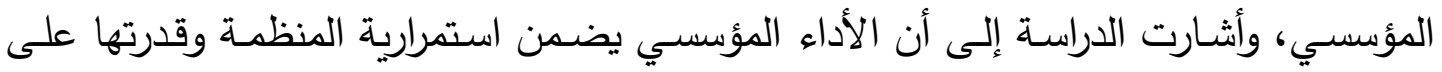
المنافسة، وتوصلت الدراسة إلى : أن الادارة الاستراتيجية تمكن المنظمة من التخطيط والتوظيف والاختيار والتدريب والتتميـة المهنية للعاملين ، وتحقق الأداء المطلوب والحصول على مزايا

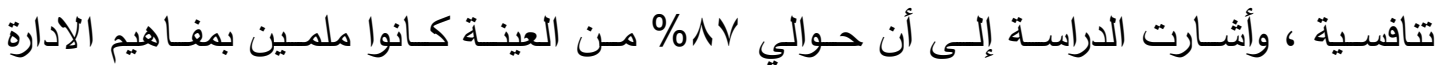
الاستراتيجية ، وأن • v\% من المنظمات تستطيع تطوير الأداء المؤسسي من خـلال إدارتها

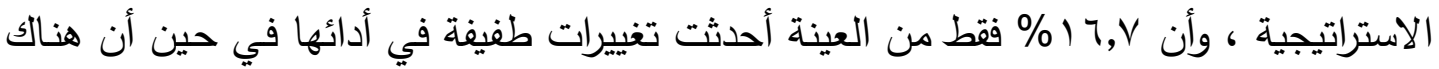

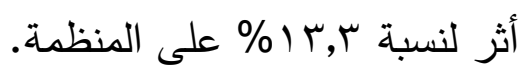

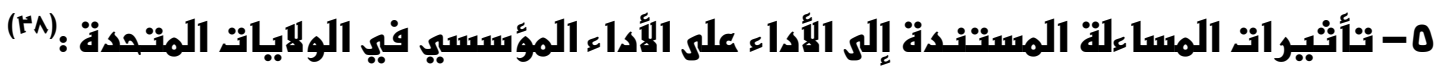
هدفت الدراسة إلى : قياس الأداء المؤسسي من خلال مؤشرات تعليمية وبحوث تمثيلية، معدلات التخرج ومستويات تمويل البحوث الفيدرالية ، وتحليل التغيرات في الأداء المؤسسي بعد اعتمـاد معـايير مسـاءلة جديدة ، واستخدمت الدراسـة : النمذجـة الخطيـة ، وتوصـلت الدراسـة لمجموعة من النتائج منها: أن الدول التي اعتمدت على المساءلة على أساس الأداء لم تثهد زيادة ملحوظة في الأداء المؤسسي.

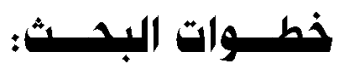

يسير البحث الحالي - تحقيقا لأهدافه - وفق الخطوات التالية:

أولا: الاطار النظري للقيادة المستدامة من حيث : المفهوم والمبادئ والاهمية والأبعاد في الفكر

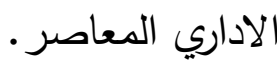

ثانياً: الاطار النظري لتجويد الأداء المؤسسي من حيث : المفهوم والخصائص ومقومات الأداء

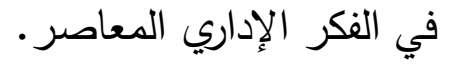

ثالثاً: طرح مجموعة من المقترحات التي تسهم في تجويد الأداء المؤسسي بالمدارس الثانوية

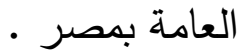




\section{1/1 - الإطار المفاهيمي لاقبيادة المستتدامة :}

تتعدد وتتنوع أنماط القيادة وتتشـابه جميعها في السعي نحو تحقيق أهداف المدرسـة،

فالجميع يسعى إلى تحقيق النجاح والتميز بشكل مستمر في جميع الجوانب، وذلك دون إهمال أي جانب لأن ذلك يساعد في النجاح والتقدم، وتتميز القيادة المستدامة باهتمامها بعملية التعليم والتعلم واستمراره وهو ما يميزها عن غيرها من الممارسـات القيادية الأخرى، و يمكن تعريف لهـ القيادة المستدامة بما يلي:

فهي تعرف على أنها عملية الحفاظ على تطوير التعلم داخل المؤسسة التعليمية، ونشر

ثقافته ليستفيد منها جميع الأفراد العاملين بالمدرسة في الحاضر والمستقبل.(وج) ويرى Andy أنها المسئولية المشتركة، وأنها لا تستخدم الموارد البشرية والمادية دون مبرر بل إنها تولي اهتمامـاً كبيراً بالابتعاد عن أي ضـرر قد يقع على محيط البيئة التعليميـة

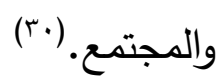
كما أنها القيادة الداعمة لإيجابية التأثير في العاملين بالمدرسة لتحقيق أعلى مستوى من غايات المدرسة في إطار شراكة مهنية مع كافة العاملين بما يضمن استدامة المستوى الإنجازي

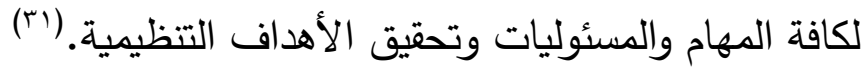
لذا فهي القيادة التي تهتم بمواجهة احتياجات الجيل الحالي دون المساس بقدرة الأجيال المستقبلية على تلبية احتياجاتهم.(r) وتعرف على أنها الحاجة إلى تحول القيادة من الوضـع الراهن إلى تعديل وتحسين الممارسات والمعتقدات والمواقف وتطوير المهارات ذات الصلة بالاستدامة والتي لم يسبق لها مثيل. (r) وتعرف أيضاً على أنها القيادة التي تعتمد بشكل أساسي على تطوير المدرسة من خلال التعلم المستمر إذ أن الهدف منها هو تحقيق ميزة تتافسية مستدامة وتوجيـه المسـار نحو التحسين المستمر من خلال عملية التعليم المستمر والتكيف مع المتغيرات بشكل أفضل من المنافسين.(๕؟) وتعـرف أيضـاً على أنهـا أي سـلوك أخلاقي لـه تـأثير على مجموعـات مـن النـاس لمساعدتهم على تحقيق النتائج البيئية والاجتماعية المنشودة.(ro() ويتبين من خلال التعريفات السابقة أن القيادة المستدامة تسمح لقيادة المدرسة بتحقيق ميزة تتافسية وتوجيه المسار نحو التحسين المستمر ، والإفادة من الموارد البشرية والمادية بأقصى 
درجـة ممكنة دون استنزافها، وتعزيز أداء المدرسة وتعميق عملية التعلم للى جميع العاملين بالمدرسة، وتحمي وتطور الحاضر وتعد للمستقبل بأهداف طويلة المدى، وتولي اهتماماً بالبيئة

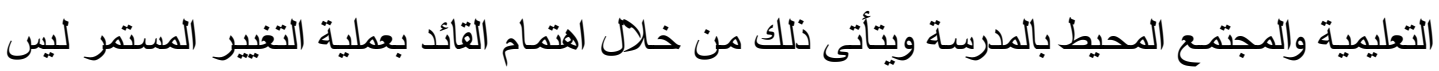
الوقتي بحيث يصبح جزء لا يتجزأ من المؤسسة التعليمية واستمرارها كنمط من أنماط العمل.

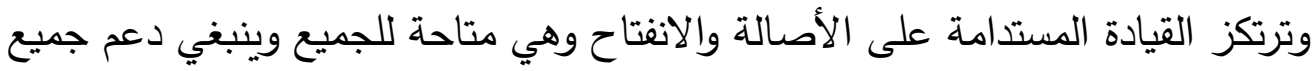

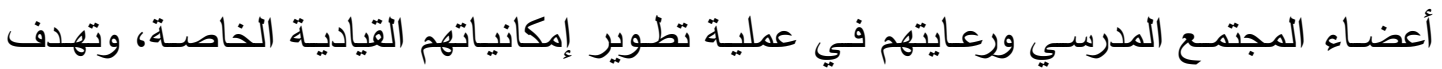

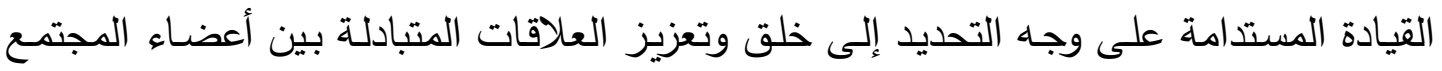

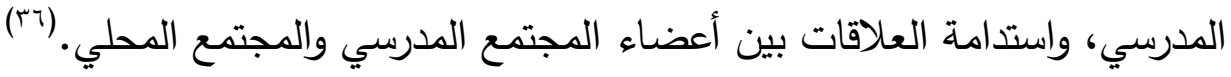

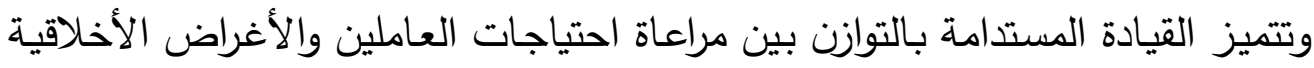

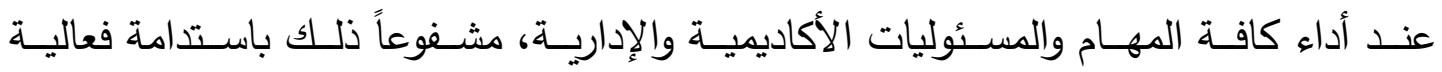
الأداء المتميز. (rv)

ويوضح الثكل التالي رقم (1) الإطار المفاهيمي للقيادة المستدامة

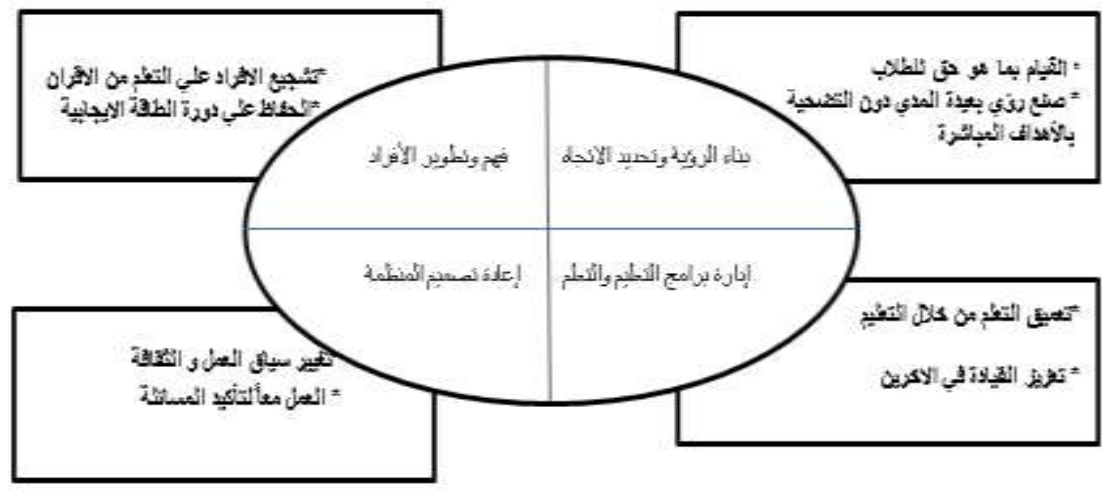

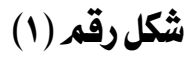

\section{الإطار المفاهيمي للقيادة المستلامة}

*source: Rosland Ann Hardie:"_Principals' perceptions of the essential components of sustainable leadership and implications for succession planning at the elementary school level",PHD.university of Saskatchewan، Saskatoon`December, 2011, p. 67

ويتضـح مـن الثـكل السـابق أن الإطـار المفـاهيمي للقيـادة المستـامة يتميز بأربعـة

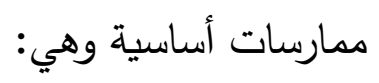

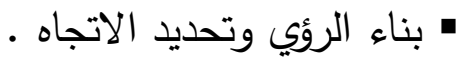




$$
\begin{aligned}
& \text { - تطوير وفهم الأفراد. } \\
& \text { • إعادة تصميم المنظمة. } \\
& \text { - آليات برامج التعليم والتعلم. } \\
& \text { كما يتضح من الشكل السابق ما يلي: }
\end{aligned}
$$

• استدامة تطوير المناهج الدراسية من منظور المتطلبات المحلية والمقتضيات الدولية.

$$
\text { الإنماء الثامل للمعارف التنظيمية للعاملين وقدراتهم الذاتيه. }
$$

- اسـتيفاء كافـة شـروط الممارسـات الأفضـل أكاديميـاً وإداريـاً على كافـة المسـتويات

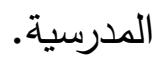

- التوازن بين رغبـات المستفيدين من الإنتاجيـة المدرسية ومقتضـيات التدابير الفعالـة

$$
\text { للإنجاز المؤسسي. }
$$

• إن القيمة الحقيقية للممارسات المستدامة وجدت في استخدام الاستدامة كقوة وراء أي

$$
\text { ابتكارات أو تقنيات جديدة. (ra) }
$$

وتهدف القيادة المستدامة أيضـاً إلى بناء وغرس العلاقات المستدامة وتعزيز الثقة مـع

$$
\text { المستفيدين داخل وخارج المؤسسة التعليمية.(•؛) }
$$

إن عـداً مـن أطـر القيـادة المسـتدامة تشـير إلى أن التعلم يجـب أن يثـمل التتميـة والتحسين المستمر ، وأن يكون هنالك فرص لجميع أعضـاء المجتمع المدرسي، ويبرز خلالها أيديولوجية بناء القدرات التي تؤكد على ضرورة إتاحة الفرصة لجميع الموظفين، وبالتالي فالقيادة المستدامة تدعو لأهمية كل من المدير والموظفين في قيادة المؤسسة التعليمية، ومما لاشك فيه أن تتمية قدرات الموظفين والمدراء القيادية لها أهمية قصوى في الارتقاء بالمؤسسات التعليمية في هذا العصر سريع التغير. (1) وممـا سبق يتضـح أن القيادة المستدامة هي نمط قيادي حديث ومتكامل يهتم بكافـة جوانب العملية التعليمية، مما يضـن بناء المؤسسات التعليمية بناءاً قوياً موجهاً نحو مستقبل ناجح ومستدام، وتوفر القيادة المستدامة خارطة طريق وأفضل الممارسات التي يمكن استخدامها في هيكلة نهج الإدارة لاستدامتها بغض النظر عن حجم المؤسسة التعليمية، وهي تعني ببناء قدرات جميع العـاملين بالمجتمع المدرسي، وتسعى للإفـادة من الموارد الماديـة والبشرية دون إهدارها أو ضـياعها دون فائدة، فـالجميع في المـارس التي تـدار بالقيـادة المستدامة يسعى 
لتحقيق النجاح المستدام والتحسين المستمر في جميع جوانب المدرسة، ومن المؤكد أن هذه

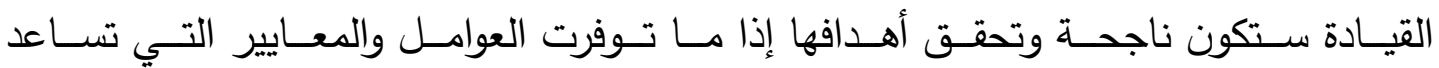

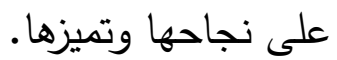

\section{(2r) : r/1 - أهمية القيادة المستدامة في المؤسسات التعليمية}

" أنها ضرورية للحفاظ على الثقافة المدرسية الإيجابية، والروح المعنوية العالية بين أعضاء العهاء

$$
\text { المجتمع المدرسي. }
$$

ه هشاركة جميع أعضاء المجتمع المدرسي في وضع رؤية المدرسة ورسالتها.

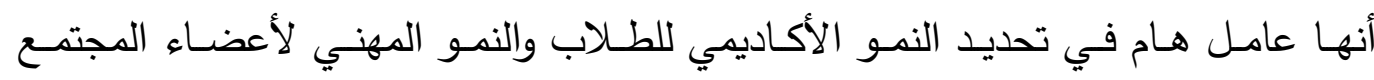
المدرسي.

أن قدرة القائد المستدام في جعل أعضـاء المجتمع المدرسي لديهم مسئولية مشتركة، يعد عنصراً هاماً في تحقيق الأهداف طويلة وقصيرة الأمد. تعزز الأفكار والممارسات الناجحة في مجتمع التعلم، وتحسن استثمار الموارد البشرية و

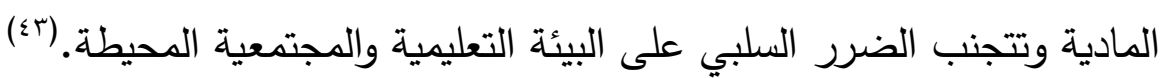

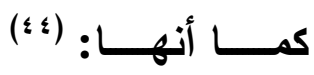
تدعم تجريب الأفكار الإبداعية واستدامة التطوير التنظيمي للهياكل والمستويات الإدارية في

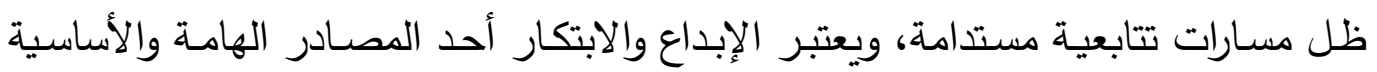
للتقدم في أي مؤسسة تعليمية. وتستمر المدارس ذات القيادة المستدامة في البحث والتطوير طويله الأمد.

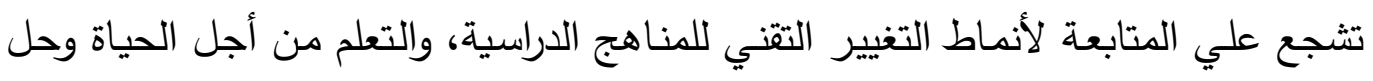

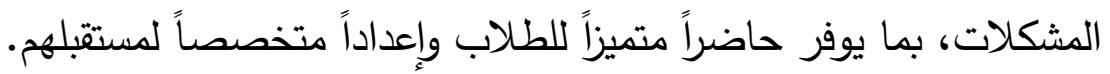
تعزز القدرات القياديـة لاستـامة القيادة داخل مجتمع التعلم، عن طريق إطـلاق العنـان

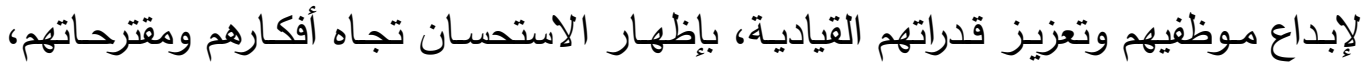

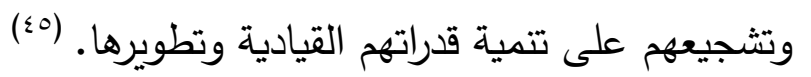
وتعمل القيادة المستدامة على بناء جيل جديد ومؤهل من القادة داخل المدرسة، ولديه

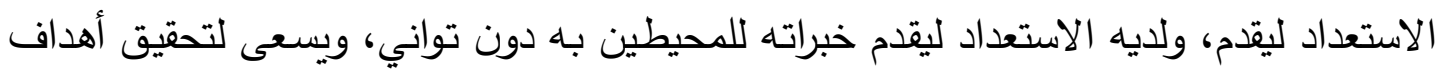


المدرسة طويلة الأمد المستدامة دون التضحية بالأهداف قصيرة الأمد المؤقتة ويعد هذا مؤشراً

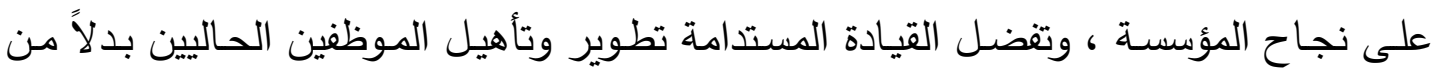

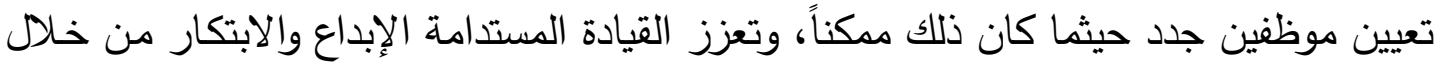
محاكاة الأفكار المبتكرة والجديدة.

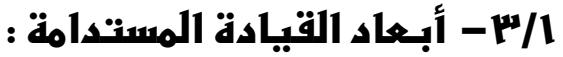

للقيادة المستدامة ستة أبعاد رئيسة وفيما يلي شرح لكل بعد من هذه الأبعاد:

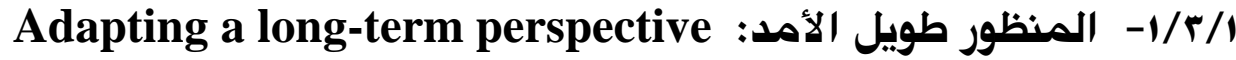

تعد السمة الرئيسة التي تميز للمدارس المستدامة عن غير المستدامة، هو أن إدارتها تتبنى رؤى طويلة الأمد، ويعد التوازن بين المنظورين طويل الأمد وقصير الأمد أمراً أساسياً لأي مدرسة تسعى للنجاح إلا أنه قد يكون من الصعب تحقيق ذلك حينما تطغى النظرة القصيرة الأمد على الأهداف طويلة الأمد، إن تبني منظور طويل الأمد يمكن للمدرسة من تحقيق التميز

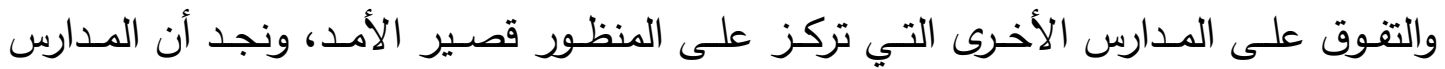
المستدامة تعمل على تحقيق التوازن بين الاعتبارات قصيرة الأمد وطويلة الأمد، والتي تتراوح بين التفكير الاستراتيجي، والتخطيط الاستراتيجي وعمليات النمو، والعمل على تطوير الموظفين

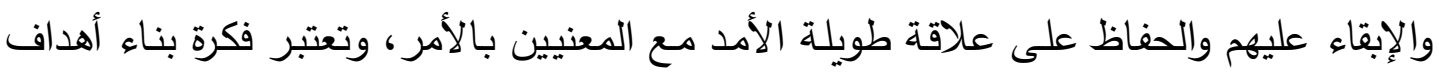

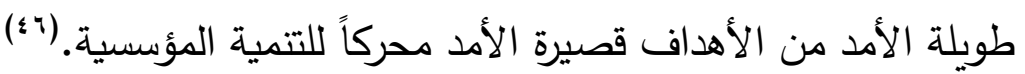

\section{H/r/r/r- تنميتة الموارد البشريتة: Human resources development}

وطبقاً للقيادة المستدامة فإنه يفضل تطوير وتدريب أعضـاء المجتمع المدرسي داخل

الددرسة بدلاً من جلب طاقم عمل أو موارد بشرية من خارج المدرسة، لأن ذلك يعتبر قراراً

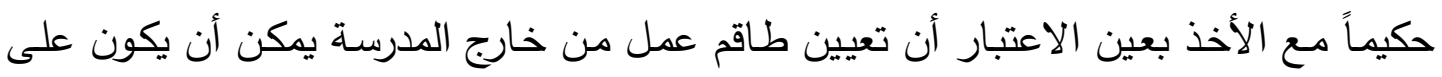

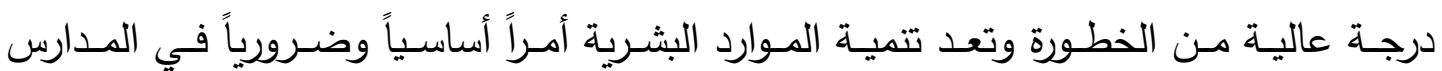
المستدامة، وتركز القيادة المستدامة على الاستثمار في الموارد البشرية والسعي المستمر لتتمية مهارات الموظفين بطرق متتوعة، من خلال أساليب تطبق داخل الددرسة ،أو غيرها من أشكال التدريب الرسمي، والتدريب أثناء الخدمة، وبرامج الدراسات العليا وغيرها، كما يتسم التدريب في

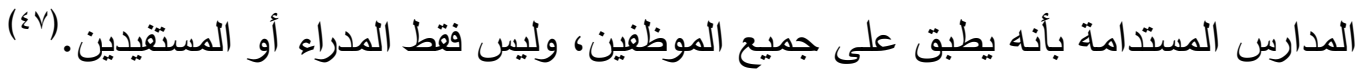




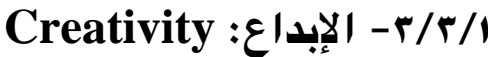

يسـاعد الإبـداع المدارس المستدامة في الحفـاظ على أدائها والتكيف مـع المتغيرات المحيطة بها، ومـن ثم فإن المدارس المستدامة تستثمر استثمارات طويلة الأمد فيما يعرف بالبحث والتطوير حتى في أصعب الظروف ،وذلك لمساعدتها على التوصل لحلول أصيلة وغير تقليدية، وعلى العكس من ذلك فقي المدارس غير المستدامة فإن ممارسة الإبداع طويل الأمد يعد أمراً في غاية الصعوبة ، حيث يتم تقليص التدريب والتطوير المقدم لفريق العمل وذلك ملك

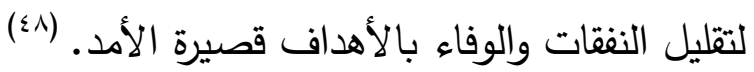

\section{Organizational culture:ع///الثقافتة التنظيميتة}

تتضـمن المدارس المستدامة ثقافة تنظيمية قويـة وهي عبارة عن مجموعة من القيم والمعتقدات المشتركة التي تسود لدى الموظفين في مؤسسة معينة، وتحاول المدارس المستدامة إبراز هذه القيم التي تجهـع أعضــاء المدرسـة معـاً حتى في ظل تعرض المدرسـة لتغيرات استراتيجية أو إجرائية رئيسية، أو حتى في أصعب الأوقات التي تواجهها المدرسة، وتحدد القيم والمعتقدات القواعد التي يتعين على أفراد الدرسة العمل في ضوئها، وتساعد الموظفين على تحديد السلوكيات المرغوبة، ومن ثم فإنها تحدد القواعد الإجرائية التي تستند إليها ثقافة المدرسة، وعادة ما يتم إدارة الثقافة من خلال بيانات الرؤية، والقيم، والفلسفة، والبيانات التي تعبر عن

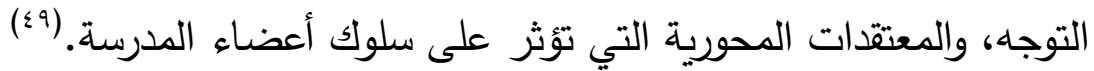

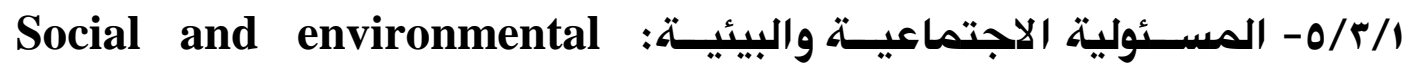
responsibility

تتبنى المدارس غير المستدامة اعتقاداً رئيسياً وهو أن مهمتها الأساسية هي العمل على تحقيق الأهداف قصيرة الأمد، ومن ثم فإنه يمكن إهمال جميع الأنثطة التي يمكن أن تبعد المدرسة عن تحقيق هذا الهلف الرئيس من قبل ممارسة المسئولية الاجتماعية أو المشاركة في مبادرات حماية البيئة، وخلافاً لذلك فإن الددارس المستدامة تمارس المسئولية البيئية والاجتماعية ليس فقط للأسباب النفعية من قبيل الوفاء بمتطلبات القانون، ولكن نظرا لأن هذه المسئولية تعمل على تحقيق فوائد للمؤسسة. 


\section{Ethically behavior :}

ويشير السلوك الأخلاقي بثكلٍ أساسي إلى فعل السلوك الصحيح ووفق التعريف فإنه

مفهوم يصعب تعريفه بشكل دقيق نظراً لاختلاف مفهوم السلوك الصحيح من فرد لآخر ، ومع الصع

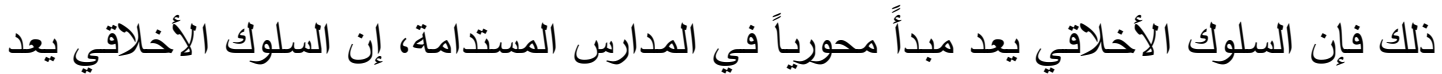
أمراً حاسماً للاستدامة التظظيمية، وعلى الرغم من جهود المشرعين لإجبار المدارس على الععل

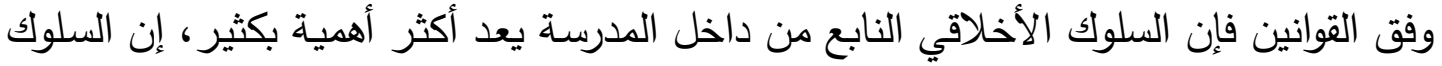

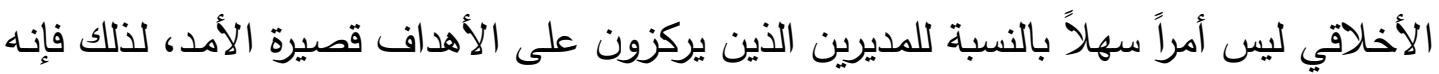

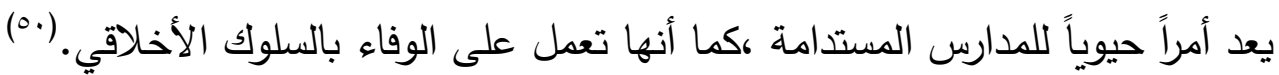

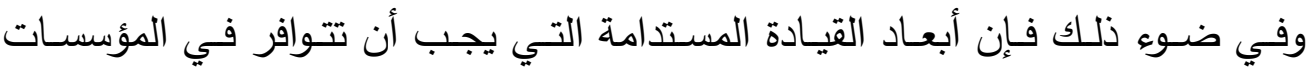

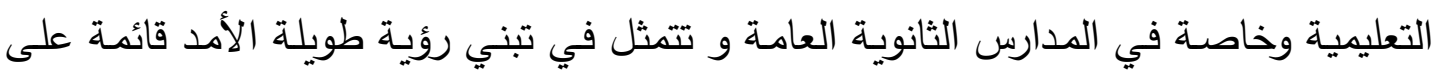

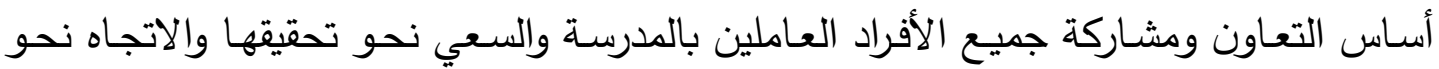
تتمية الموارد البشرية واستثمارها من خلال تدريب العاملين بالمدرسة أثناء وبعد العمل، واستثارة

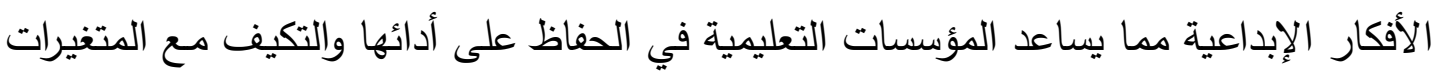

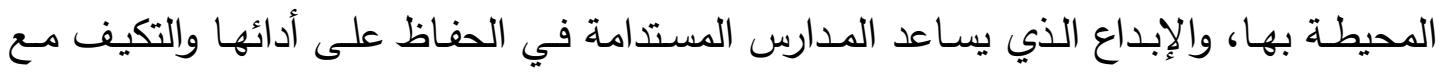

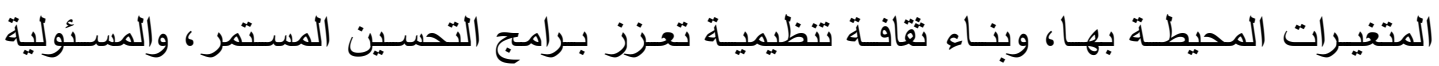
الاجتماعية والبيئية التي تعمل على تحقيق فوائد للمدرسة، السلوك الأخلاقي الذي لهي يعد أمراً محورياً في المدارس المستدامة.

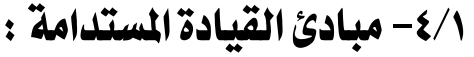

تقوم القيادة المستدامة على مجموعة من المبادئ التي تتوافق مع سعي القائد الناجح والمبدع للارتقاء بمؤسسته وتحسين أداء العاملين، واستثمار الموارد المادية والبشرية المتاحسة بالثكل المناسب، وبما يضمن بيئة مواتيه للعمل المثمر والجاد الحاضر والمستقبل، ويمكن بيان

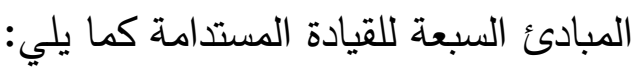

\section{1/2/1 - القيادة المستدامة تظلقة وتصافظ على استدامة التعلم:}

\section{Sustainable leadership creates and preserves sustaining learning}

وتعنى استدامة التطوير التعليمي من خـلال إثراك الطلاب والمعلمين والإداريين في

كافـة النواحي الفكريـة والاجتماعية ليس فقط لتحقيق نتائج مرغوب فيها ولكن أيضـاً لتحقيق الأمور الأكثر عمقاً التي تكمن وراء التعليم، مع مواكبة كافة المستجدات عالمياً في مجال التعليم، 
فالمسئولية الأساسية لجميع القادة تتمثل في الحفاظ على التعلم، لذلك فالقيادة المستدامة تعزز استدامة واستمرارية التعلم، لتحقيق انجازات وتحسينات دائمة في التعلم تكون قابلة للقياس.(1) r/L/1 - القيادة المستدامة تطور وتنـمي الموارد البشرية :

\section{Sustainable leadership develops human and material resources}

فالقيادة المستدامة تتمي وتطور الموارد البشرية ولا تستزف المادية، وتعترف بالمواهب

القياديـة للمؤسسـة وتكافئهـا، وذلك مـن خـلال اجتذاب القـادة الداعمين لتتميـة و بنـاء القدرات الأكاديمية والإدارية لجميع أعضاء المجتمع المدرسي، والتي تساعد على تطوير العمل الإداري،

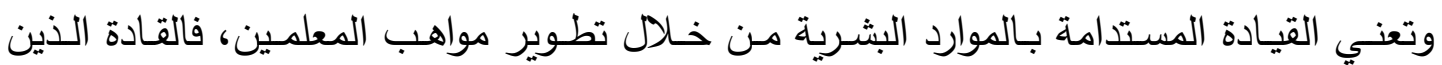
تعرضوا للاحتراق الوظيفي بسبب المطالب المفرطسة والموارد المتناقصـة، لا يمتلكون الطاقـة الكافية ولا القدرة العاطفية لتطوير وتغيير مجتمعات التعلم.(هr)

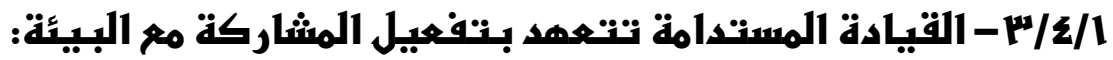

Sustainable leadership undertakes activist engagement with the environment

أي تتعهد القيادة المستدامة بالمشـاركة الفعالـة في كافـة الفعاليـات والأنثطة البيئيـة المحيطة بالمؤسسة التعليمية، الأمر الذي يبرهن على كون القيادة المستدامة تخلق مستقبلاً

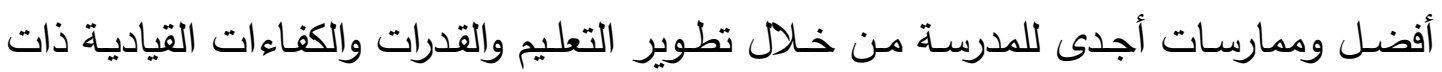

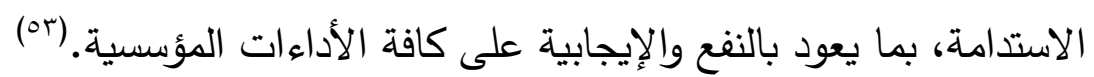

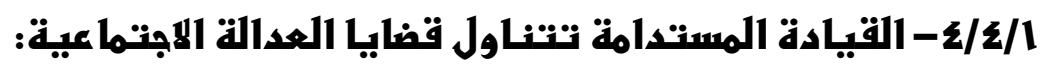
Sustainable leadership addresses issues of social justice أي تحرص القيادة المستدامة على نشر العدالة التتظيمية بالمؤسسة التعليمية، وتلبية احتياجات أعضاء المجتمع المدرسي على حٍِ سواء، فهي عملية مترابطة لذا فهي تمتلك آليات

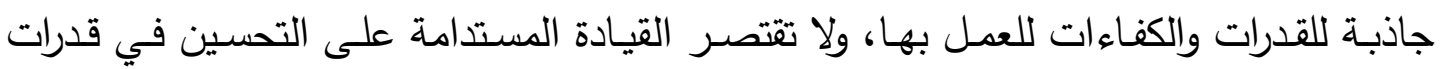

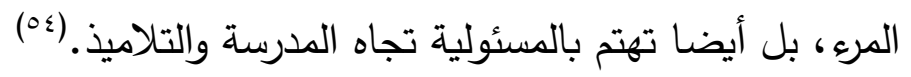

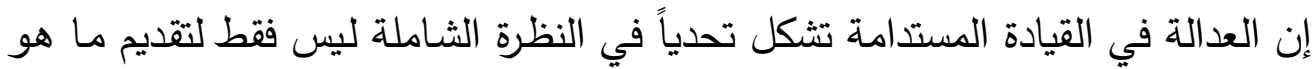

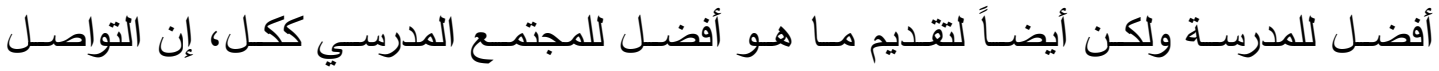
الاجتماعي للقادة لا يخدم العاملين بالمدرسة فقط بل يهدف إلى تحقيق التميز لددرستهم، إن 
القيادة المستدامة منصفة اجتماعياً وتركز على الصالح العام للجميع، وليس فقط للعاملين داخل

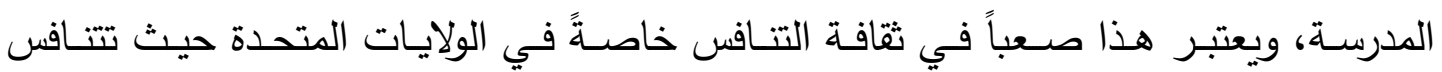

المدارس مع بعضها البعض على الجودة العالية للمعلمين، ودافعية الطلاب، والتمويلات. (00)

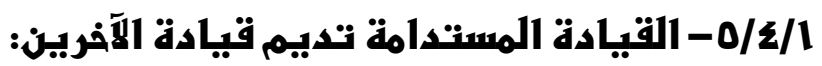
Sustainable leadership sustains the leadership of others وذلك يعني توزيع القيادة في جميع أنحاء المدرسة، مع تكليف جميع العاملين بالمشاركة

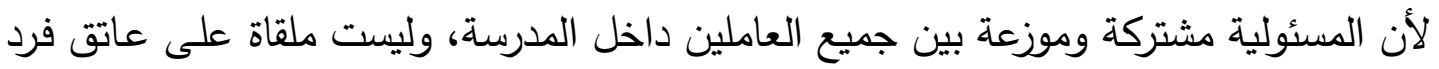
معين ،فالجميع مطالب بالمشاركة من خـلال تبني خطط التحسين المستمر والدائم داخل المدرسة، ومن الطرق التي تديم قيادة الآخرين ضمان مشاركتهم في تحمل المسئولية، وتطوير

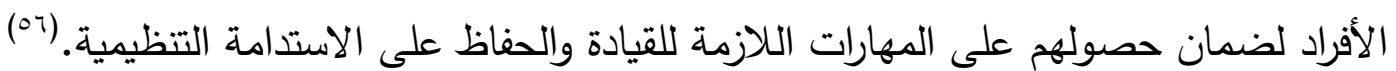

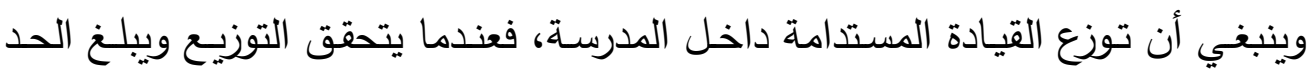

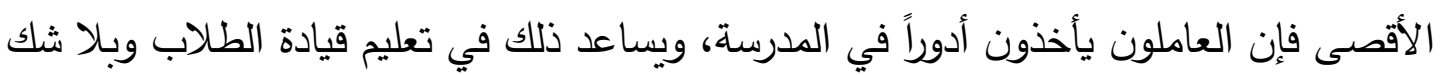

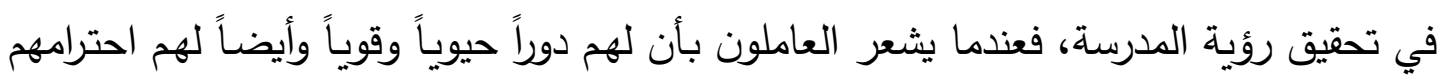

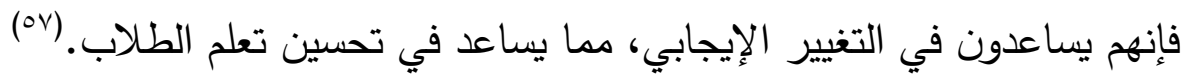

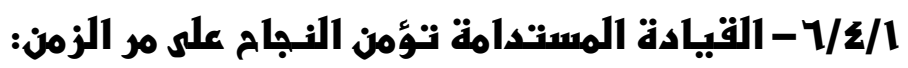
Sustainable leadership secure success over time

يعد التعاقب القيادي هو جوهر أداء القيادة المستدامة، فهي تخطط وتستعد للتعاقب القيـادي، لـيس باعتبارهـا فكرة لاحقـة لكن مـن اليوم الأول لتعينين المدير، وتتطلب القيـادة المستدامة إيلاء اهتمام جدي للتعاقب القيادي، ويتم تحقيق التعاقب الناجح من خلاد إلباء التهاء القادة

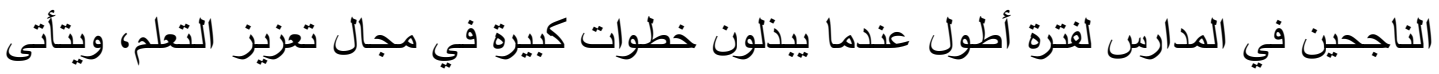

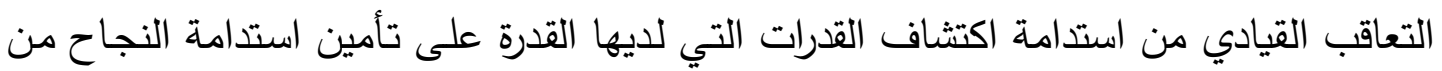

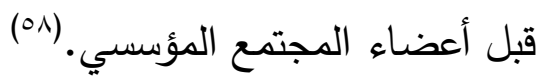

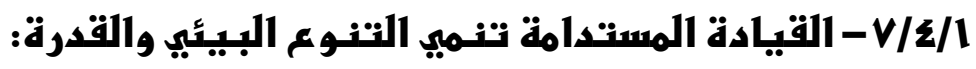
Sustainable leadership develops environmental diversity and capacity

إن التميز الإداري للقيادة المستدامة يقتضي تتوعاً تجاه بناء القدرات الأكاديمية والإدارية

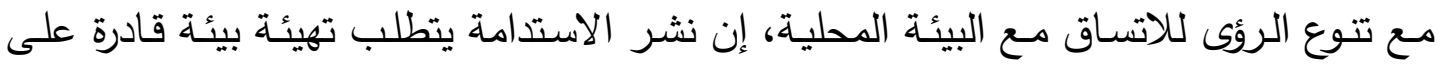


التحفيز والتحسين المستمر على نطاق واسح، فهي تمكن الناس من التكيف مع زيادة التعقيد

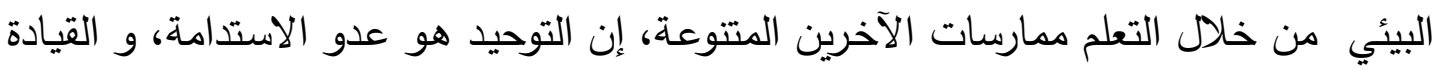

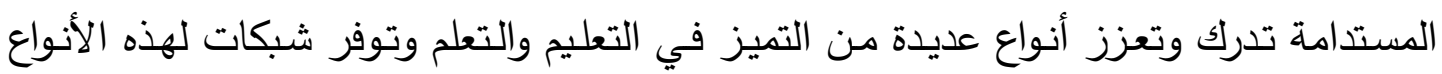

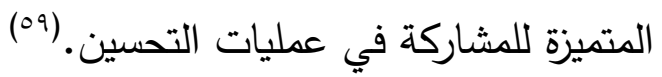
إن التتوع يسمح للمدارس بالتميز وذلك من خلال تعزيز التطلع للتنوع المعرفي والخبرة كقاعدة للموظفين، إن المدرسة تتغير باستمرار لأن العاملين بها والطلاب لديهم خلفيات متتوعة

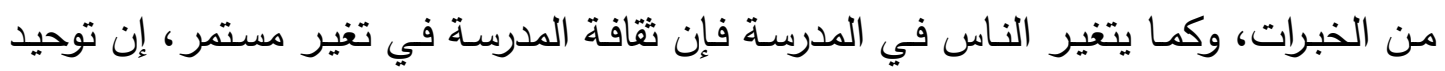

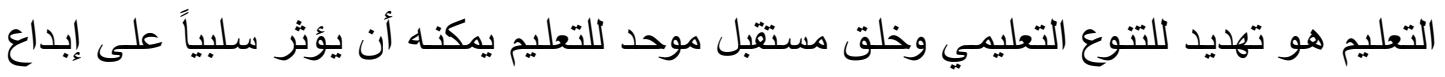

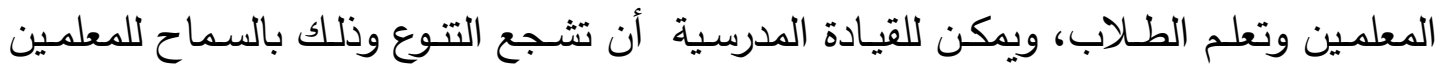

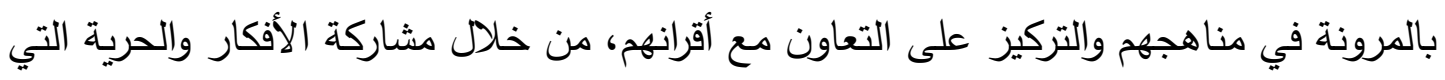

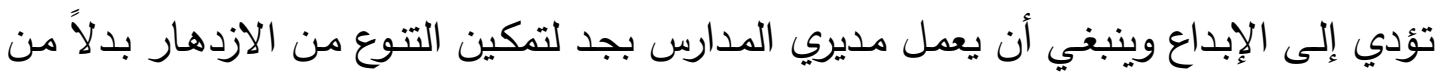

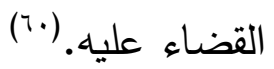

\section{ثانياً : تجويل الأداء المؤسسي :}

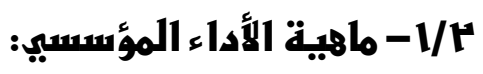

يعد الأداء المؤسسي وتطويره داخل المؤسسات من أكثر الموضوعات حداثة وأهمية في

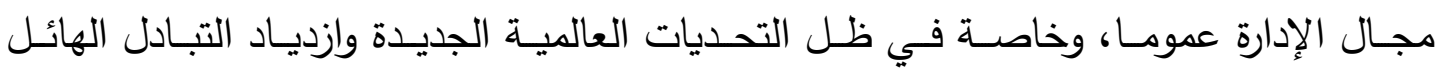
للمعلومـات، وتركـز ثقافـة الأداء المؤسسـي علـى أهميـة الإبــاع والثـفافية والكفـاءة والتميـز واللامركزية وتفويض الصلاحيات والتمكين الإداري.(1)

يعرف الأداء المؤسسي على أنه القدرة على انجاز المهام بنجاح من خلال الاستخدام

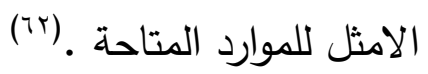

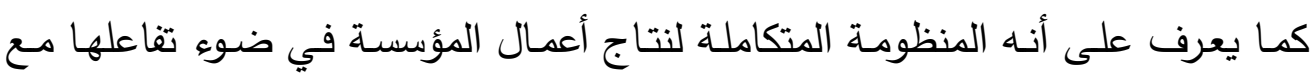

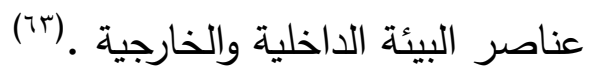
كما يرى نبيل رسلان أنه نتيجة لمجموعة من التفاعلات المعقدة التي تتم بين الموارد البشرية والمادية والبيئية التنظيمية داخل المؤسسات من جهة وبين البيئة المحيطة بهم من جهة

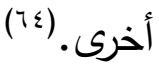


ويعرف على أنه نشاط شمولي مستمر يعكس قدرة المؤسسة على استغلال امكانياتها

وفق أسس ومعايير معينة، فإن اختلفت نتائج الأداء عما هو موضوع من المعايير، فإن الإدارة

تقوم بتصحيح الإجراءات لمعالجة الخلل بين النتائج المتوقعة والنتائج الفعلية.(70)

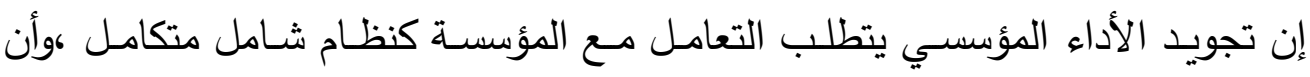
يكون هناك نوع من التواصل الفعال داخل المؤسسة ومـع بيئتها الخارجية ، وأن يكون تمكين العاملين الأساس في أداء الأعمال، مع الانتقال من محدودية الموارد إلى تتوعها واستمراريتها، كما يضمن العمل المؤسسي عدم تفرد القيادة باتخاذ القرارات واتباع اسلوب فرق العمل في حل

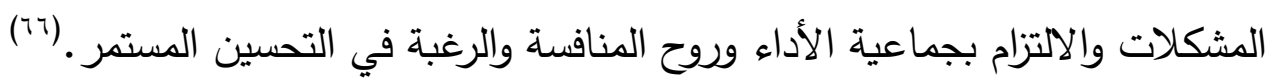

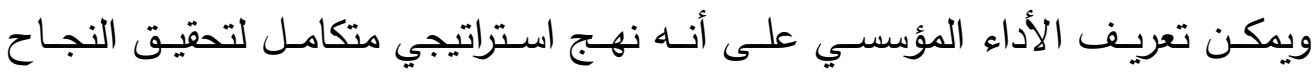
المستمر للمؤسسات من خـلال تحسين أداء وتطوير قدرات فرق العمل للحصول على الميزة التتافسية.(TV) ويتضح من خلال التعريفات السابقة أن تجويد الأداء المؤسسي هو استراتيجية تحسين

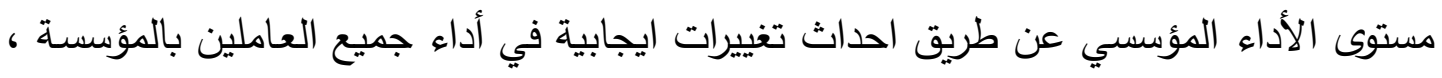
وتكون هذه التغييرات مرتبطة بالأهداف الموضوعة مسبقا من قبل القائمين على عملية التطوير بالمؤسسة.

\section{r |r/t - مقومات الأداء المؤسسي:}

هناك عدد من المقومات التي تشكل أساساً للأداء المؤسسي ومن خلالها يتم الحكم

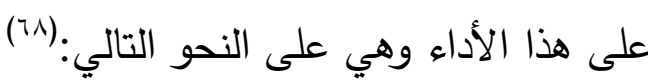

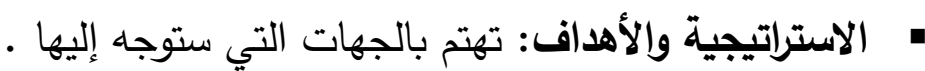

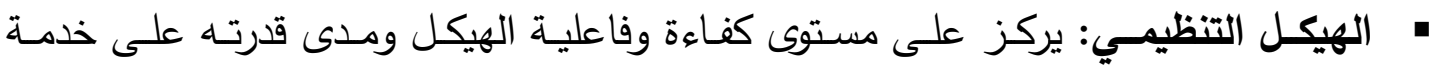

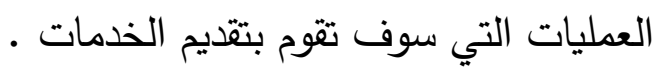
هالمقيساس: وهو الاداء الذي يمكن استخدامه بطريقـة تفيد وتخدم كـلا مـن الاستراتيجية والاهداف. • الإدارة: وتتمثل في الطريقة التي ستستخدم لتحديد المسـارات والاتجاهـات ، وكيف تقوم بعملية التصحيح أو التصويب. 
(79): إن أبرز مقومات الأداء المؤسسي تتحدد فيما يلي تبني التغيير كسياسة ثابتة على المستويات التنظيمية كافة. تشجيع المديرين على ممارسة القيادة وليس الرئاسة. التركيز على أن تكون المؤسسة رائدة في مجالها الرئيس.

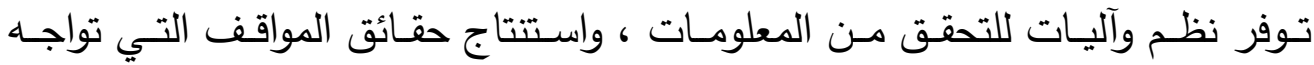

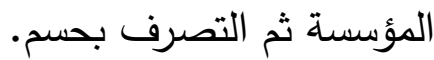

تحقيق الجودة في كل أنحاء المؤسسة ومجالات الأنثطة والخدمات المقدمة داخلها.

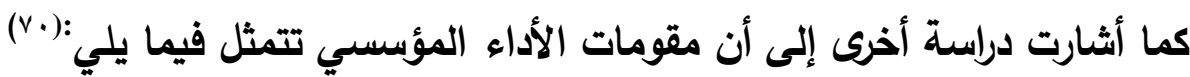
استثمار الموارد البشرية لإعادة تثكيل القدرات التتافسية واستثمارها. التزام البساطة في الهيكل الإداري ، والاتصالات التنظيمية الدفتوحة . تحقيق مستوى الاداء المتميز في مجالات وأنثطة المؤسسة.

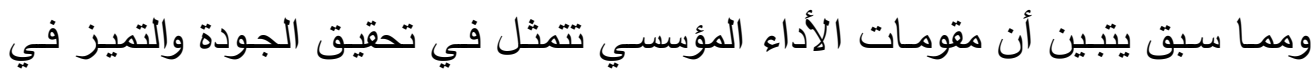

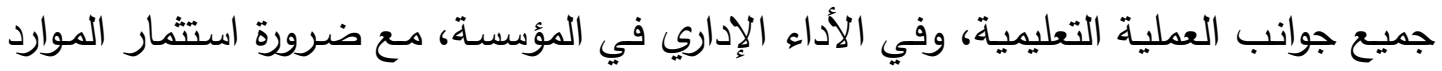

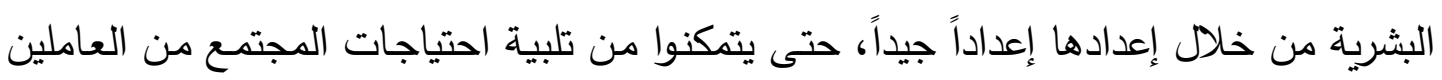
المؤهلين الذين يسهون في تحقيق الجودة للمؤسسة وتميزها عن منافسيها.

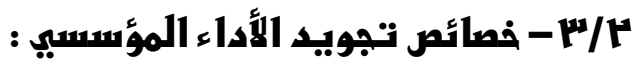

(v): تحدد خصائص تجويد الأداء المؤسسي فيما يلي زيادة رضا العاملين وهو ما ينعكس على تعزيز ولائهم وانتمائهم للمؤسسة، ما يضمن لأنس

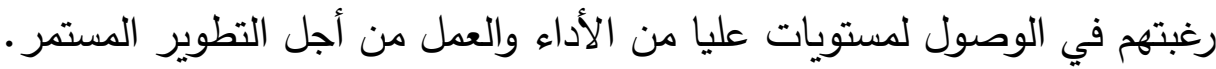

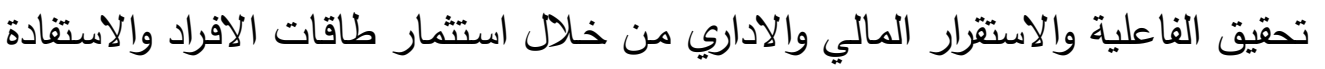

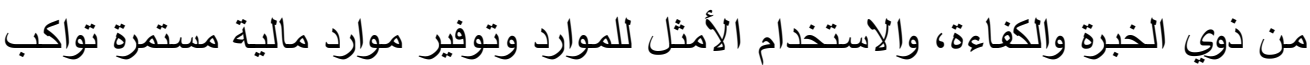
الاحتياجات المتغيرة.(rr)

يضمن العمل المؤسسي تشجيع الأفراد على التفكير وقبول الأفكار المتتوعة، واحتضـان الإبداعية منها. تعزيز الرؤية المشتركة في التخطيط والتتفيذ واتخاذ القرار بين القيادة والعاملين وأعضـاء 
توظيف الأساليب الحديثة في الإدارة ، التي تعتمد على تحقيق رضـا العملاء والسعي

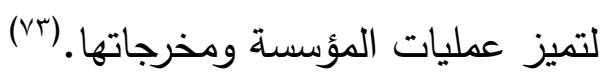

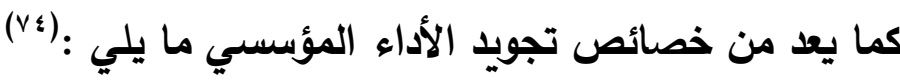

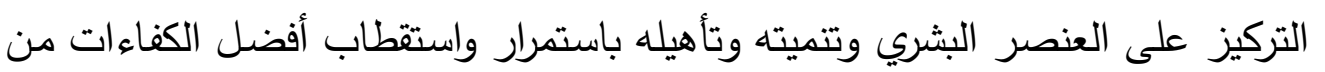
خلال سياسة متطورة تعتمدها المؤسسة في التوظيف. المحافظة على ثبات العمل واستمراره من خـلال الخبرات التراكمية والتجارب السابقة التي تثري المؤسسة، وتورث هذه الخبرات من جيل إلى جيل بحيث لا لتأثر المؤسسة

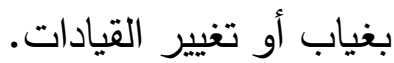
الاعتماد على جماعية الأداء والمشاركة في اتخاذ القرار من قبل المختصين والخبراء

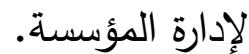
استثمار جهود كافة الأفراد العاملين في المؤسسة نحو تطوير المؤسسة في اطار واضح من الواجبات والمسئوليات، ومشاركة جماعية في تحقيق الأهداف.

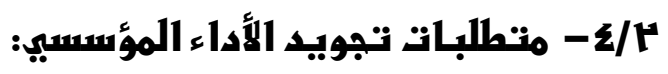
إن تجويد الأداء المؤسسي يتطلب أفراداً يمتلكون مجموعة من المهارات التي تمكنهر

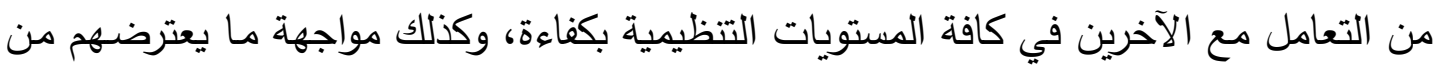

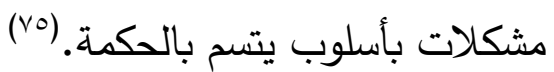

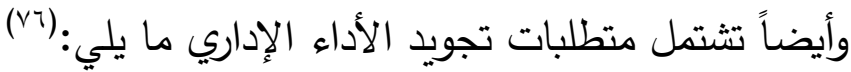
توافر رؤية مستقبلية واضحة بثأن تجويد الأداء المؤسسي. وجود خبراء متخصصين في تجويد الأداء المؤسسي.

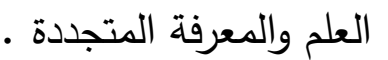
إعادة صياغة الهيكل التنظيمي. توافر الموارد المالية اللازمة لتمويل خطط واستراتيجيات تجويد الأداء المؤسسي.

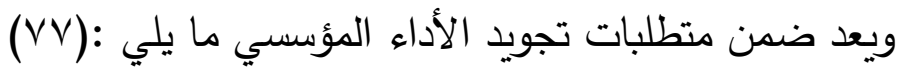
توفير معلومات كاملة عن خطة الأهداف ومستويات الجودة . تهيئة الظروف المحيطة بمكان تتفيذ العمل.

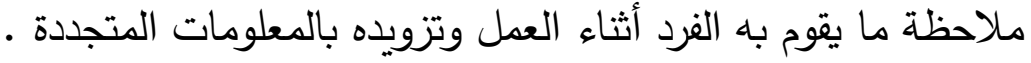


رصد نتائج التنفيذ وتصحيحها بالقياس إلى الأهداف المحددة. توفير مستلزمات الأداء المادية والتقنية من مواد ومعلومات ومعدات وغيرها من مواد الاداد يتطلبها الأداء الفعال في العمل المدرسي.

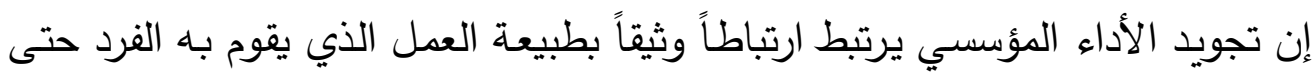

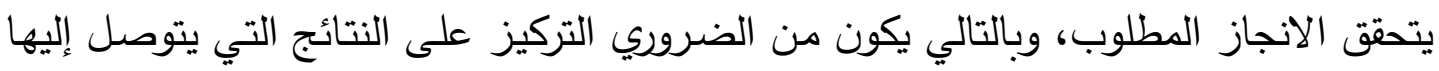

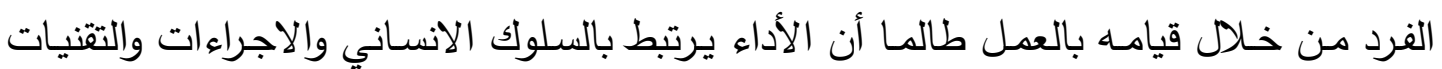

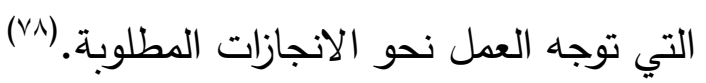

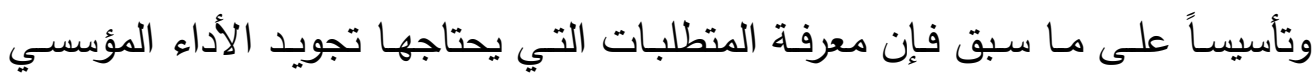

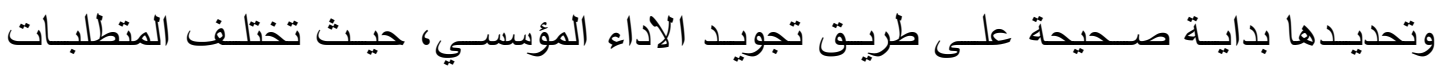

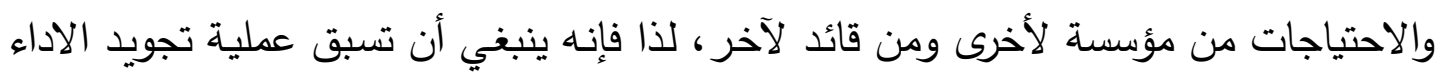

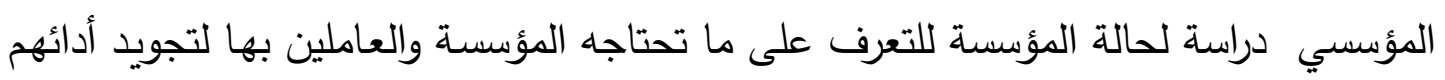
والارتقاء بمستوى المؤسسة وتحقيق الميزة التنافسية. وتثير الاتجاهات الحديثة (المعاصرة) في مجال الادارة إلى أن معظم المؤسسات التي

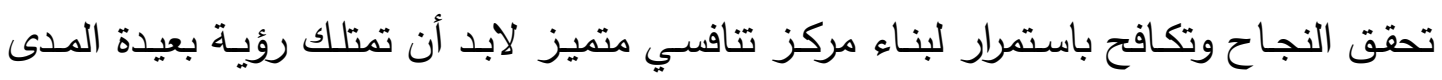

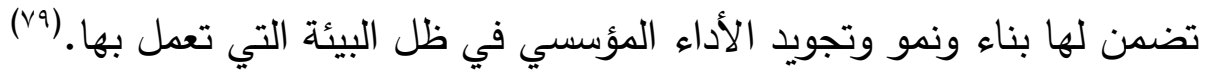

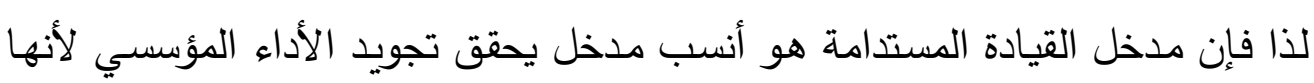
تعتمد علي الأهداف طويلة الأمد فهي تركز على بناء مستقبل مستدام للمؤسسة.

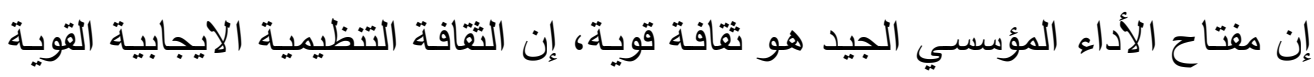

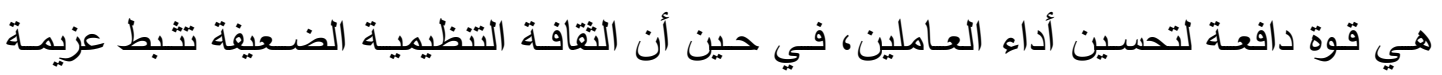

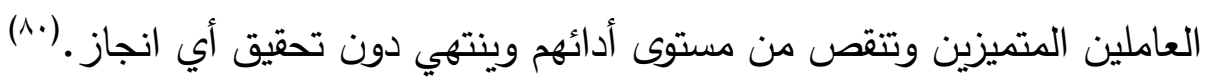

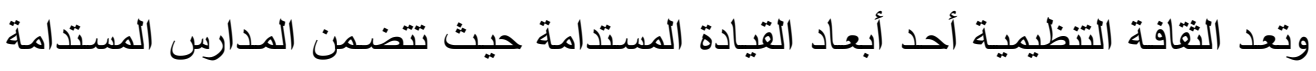

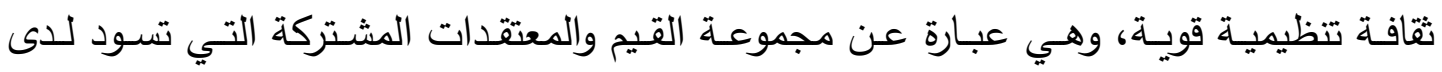
الموظفين في مؤسسة معينة، وتساعد هذه القيم الموظفين على تحديد السلوكيات المطلوبة أو

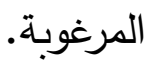
إن الثقافـة التنظيميـة مرتبطـة بـالأداء المؤسسي ولهـا دور واضـح في تحقيق الميزة التنافسية التي تسعى أغلب المؤسسات لتحقيقها.(1) 
ويعد الأداء المؤسسي أحد المحاور الرئيسة التي ينصب حولها جهود الإداريين ، كما

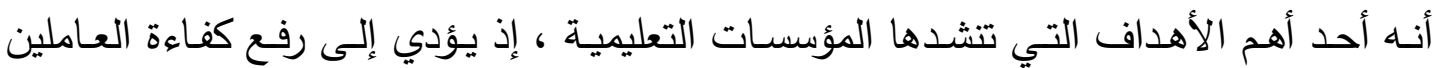

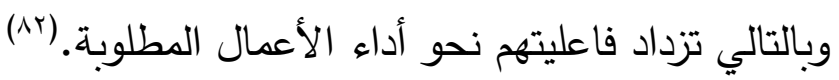
ثالثاً : المقتزحات والتوصيات:

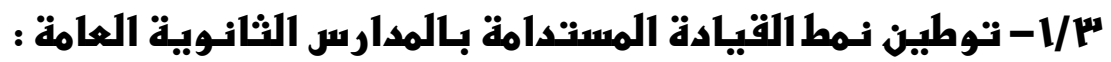
r/1/1/ إرساء ثقافة الاستدامة المهنيتة بالمدرسة من خلال: • بناء ثقافة تتظيمية تعزز برامج التحسين المستمر .

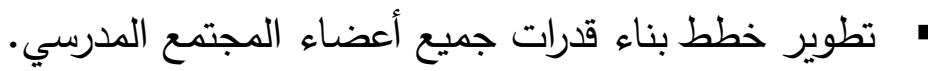

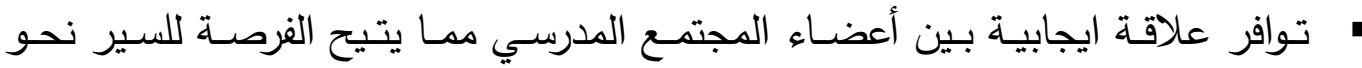
الانجاز المهني بصفة مستمرة. • تحسين قدرة أعضاء المجتمع المدرسي للقيام بكل ما هو جديد والعمل على الاستمرار في المضي قدماً نحو التميز • r/l/r/ - تنوع برامج الاستدامتة والتي تشمل :

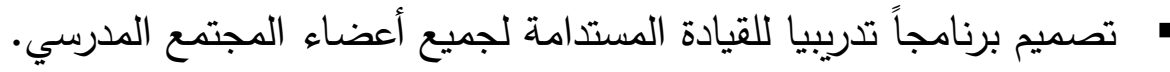
• حلقات دراسية بثكل مستمر داعمة لإرساء ثثافة القيادة المستدامة.

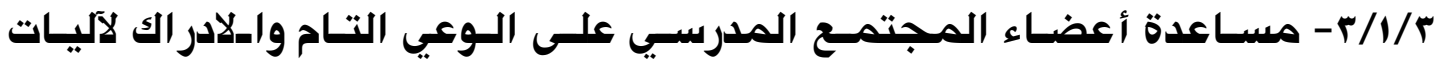
القيادة المستدامتة وذلك من خلال: عقد دورات تدريبية متخصصة في القيادة المستدامة. محاضـرات متخصصـة في الادارة التزبويـة مـن قبـل اسـاتذة متخصصسين في الادارة التعليمية. • عقد ندوات تثقيفية لتغيير الثقافة السائدة لدى أعضـاء المجتمع المدرسي عن القيادة

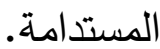

ץ/1/ا- استدامتة التحديث لكافتة أبعاد التعليم والتعلم المهني ويتم ذلك من خلال: • تثجيع التواصل وتبادل الخبرات مع الهيئات والمؤسسات ذات العلاقة مع المدرسة. • تبادل الافكار والادوار ي الدورات التدريبية بما ينعكس ايجابيا على الانجاز المؤسسي. 
• تـوفير الحواسـب الالكترونيـة للعـاملين مـن أجلـل استخدام المعـارف التقنيـة ومسـاعدة

$$
\text { الطلاب على الاستفادة من الانترنت. }
$$

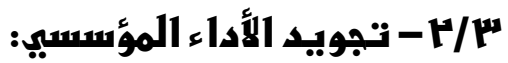

تعميم ثقافة تجويد الاداء المؤسسي في المدارس الثانويـة العامة عن طريق عقد ندوات

$$
\text { توعوية تحث على الاهتمام بتجويد الاداء المؤسسي. }
$$

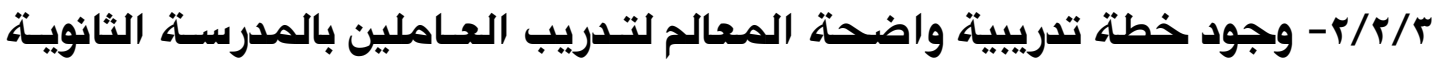

\section{العامتة بصورة دوريتة وجادة.}

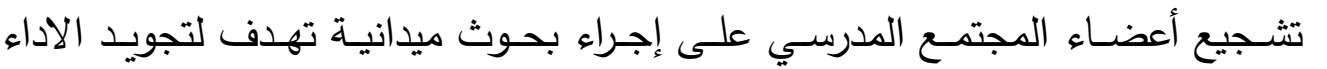

$$
\text { المؤسسي. }
$$

ضـرورة تبني وزارة التربيـة والتعليم للقيادة المستدامة كمدخل لتجويد الاداء المؤسسي بالمدارس الثانوية العامة، إذ أن هذا يعزز من قدرة المدارس الثانوية العامة على مواكبة المتغيرات ومواجهة التحديات وتلبية الاحتياجات ، وتحقيق ميزة تتافسية للمؤسسة, " إقامة دورات تدريبية وورش عمل تهتم بتجويد الأداء المؤسسي. وضع خطة زمنية مستتبلية مبنية على معايير واضحة للكثف عن المتميزين والمبدعين من العاملين بالمدرسة الثانوية العامـة ، وتدريهم لتوفير قيادات ذات كفاءة قادرة على استثمار طاقاتها على مستوى المجتمع المدرسي والمحلي لتجويد الاداء المؤسسي. 


\section{المسـراجد}

1- محمد سيد محمد :وظائف الإدارة المدرسية بالمرحلة الثانويـة العامة ، عالم الكتب ، القاهرة

$$
01 \text { ص r... ، }
$$

r- عبد الناصـر محمد رشاد ،أمل سعيد حباكة : " تطوير الأداء المؤسسي وتحقيق الميزة المستدامة بكليتي التربية بجامعتي عين شمس والمجمعة :دراسـة مقارنـة "، مجلـة الإدارة

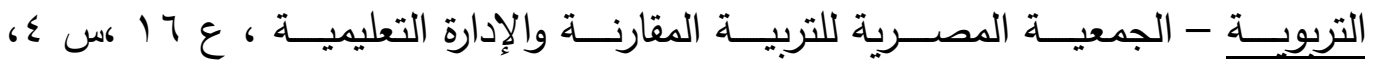
. TV מ I IV

3-Neil dempster ,et al.: Strategies to develop school leadership, A select literature review, Australian institute for teaching and school leadership( aitsl) July 2011, p.12

ع - أحمد نجم الدين عيداروس :"القيادة المستدامة ودورها في إرساء ثقافة النزاهـة التتظيمية

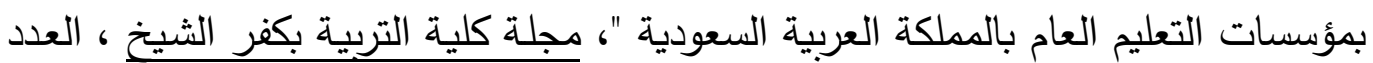

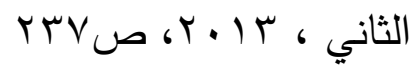

5- Tina Lynn Evans: "Leadership without Domination? Toward Restoring The Human and Natural world", Journal of Sustainability Education, Vol.2, March 2011, P.25

6- Haugland,B.K. :"Applauding sustainability leadership",forum, special Education sustainability, 2012.p.2

V- جمهورية مصر العربية، وزارة التربية والتعليم: الخطة الإستراتيجية القومية لإصلاح التعليم

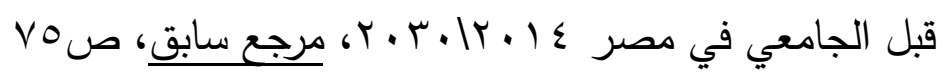

1- جمهوريـة مصر العربية: الهيئة القومية لضمان جودة التعليم و الاعتماد ، وثيقة معايير

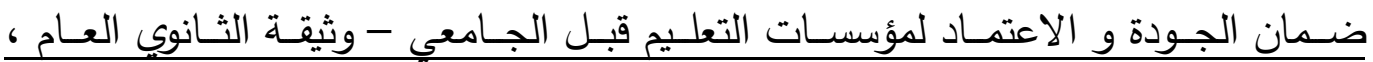

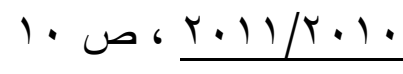

9- يحي إسماعيل محمود: " تطوير إدارة الددرسة الثانويـة العامـة بمصر في ضـوء مدخل

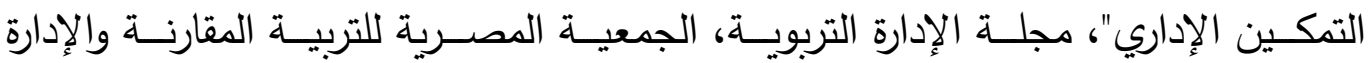

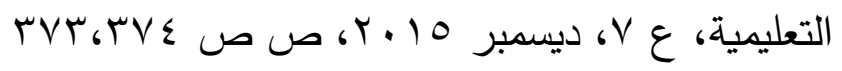

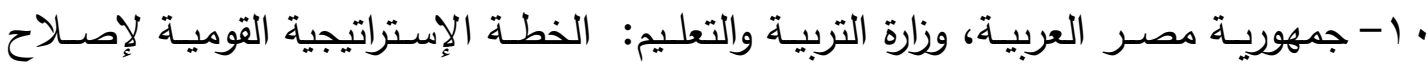

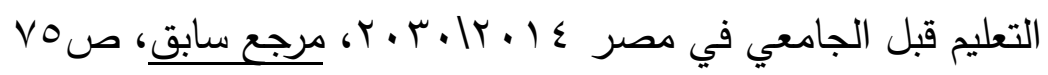


11- ناهد عزت إسماعيل: دور المنـاخ التتظيسي في فاعلية إدارة التغيير بمدارس التعليم

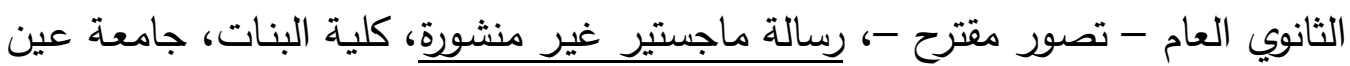

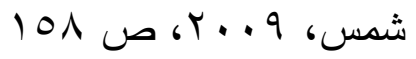

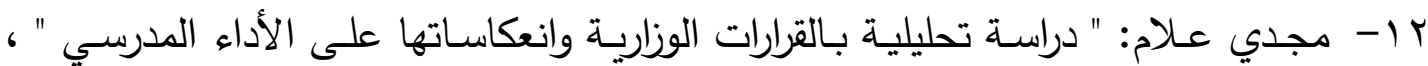

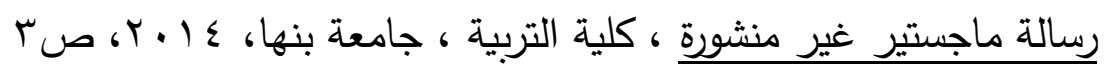

13- Brent Davies : Developing sustainable leadership, British Educational leadership, Management and administration society, Vol. 21, Issue. 3, 2007, p.8.

14- Andy Hargreaves: Sustainable leadership in education: creating the future, conserving the past.European journal of education, Vol. 42, No. 2, 2007, p. 224

10 - محمد بن علي بن مسعود : " فاعلية الأداء المؤسسي في المنظمات الحكومية "، مجلية

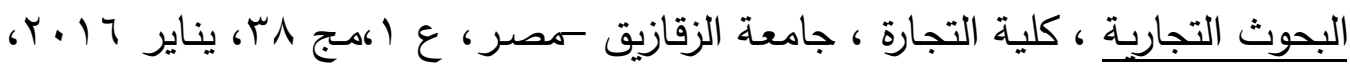
r.r 17 - مفضـي عابـ المسـاعيد : فاعلية الأداء المؤسسي للمدارس الثانويـة الحكوميـة في إقليم شمال الأردن من وجهة نظر مديري ومعلمي المدارس، رسالة دكتوراه غير منشورة ،كلية

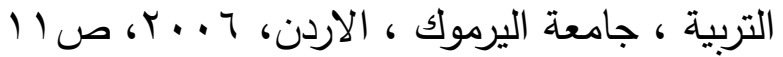

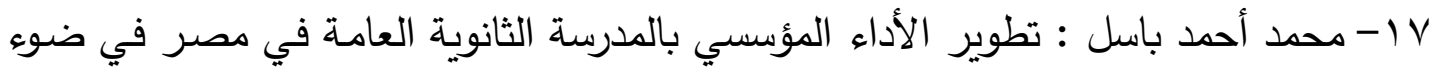

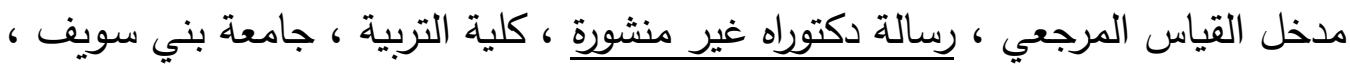
$r \cdot 11$ 11- أماني محمد يونس : درجة ممارسة مديري مدارس وكالة الغوث الدولية بمحافظات غزة

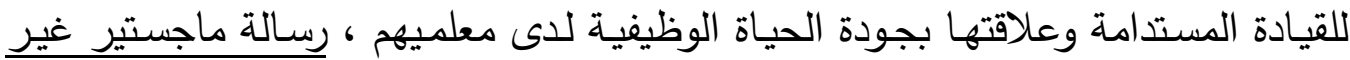

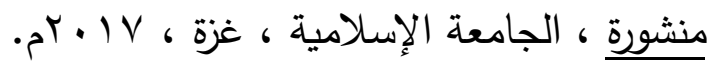

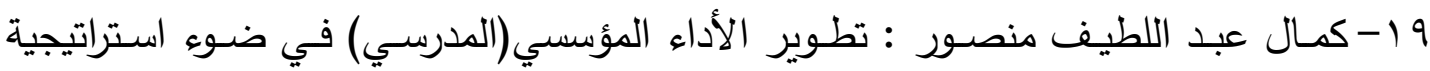
التحسين المستند إلى المدرسة : مدارس الظهران دراسة حالة ، المؤتمر الدولي الأول :

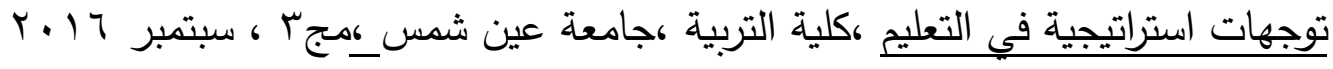

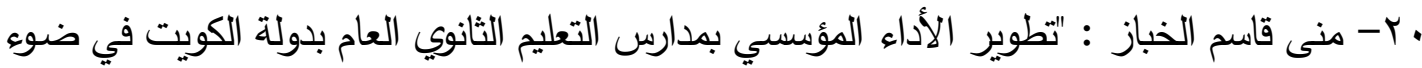

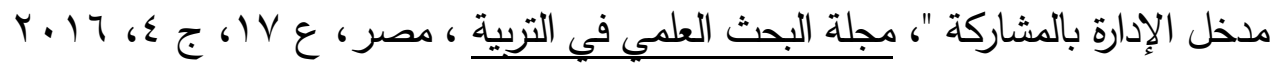


ا Y- عايدة ذيب عبد الله ،سمية مصطفى الحوامدة : "درجة فاعلية مشروع التطوير التربوي

في تطوير الأداء المؤسسي نحو الاقتصـاد المعرفي في مدارس محافظـة

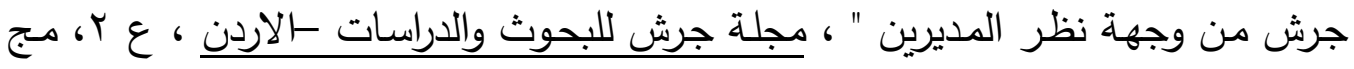

$$
r+1 \leqslant 610
$$

r r- حسين ناصـر سعد : تطوير الأداء المؤسسي لإدارات التربية والتعليم بالمملكة العربية

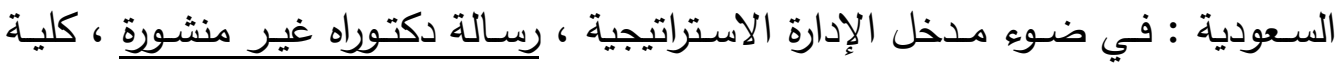

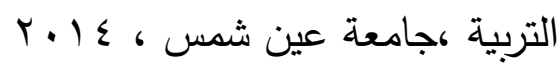

r r- أحمد نجم الدين عيداروس: مرجع سابق ،

24-Tracy Shaw : Sustainable leadership : A Delphi Study, PHD, University of Rockies, October2018

25-Lasonja Roberts : Leader self -Renewal : mind ,body, spirit , connection inherent in sustainable leadership, PHD, College of education , University of South Africa ,2018

26-Eric Joseph : Sustainable leadership : A case study examining perceptions participants in a long- term, District wide reform ,PHD, Northern Arizona university, May 2017

27-Luftim C.: The impact of strategic human Resource management organizational performance ,Economic Seria management ,Vol. 17, Issue. 2,2014

28-Jung Cheol Shin : Impacts of performance - based accountability in the U.S ,High Education, Vol. 60, No. 1, July 2010

29-Brent Davies: Op.Cit, p. 4

30-Andy Hargreaves : Op.Cit., P. 224

31-Rosland Ann Hardie :" Principals' perceptions of the essential components of sustainable leadership and implications for succession planning at the elementary school level ", PHD. university of Saskatchewan, Saskatoon , December, 2011,p.2

32-Jack Mccann\& Matthew Sweet: "The perceptions of Ethical and sustainable leadership"،Journal of Business Ethics، Vol. 121، Issue.3، May 2014، p. 375

33- Sander G. Tideman\&Et.al :"Sustainable leadership Towards a workable Definition"، The journal of corporate citizen‘No.49، March 2013،p. 30. 
33-Jari Metsamuuronen\& Et.al: "Sustainable leadership and future oriented decision making in the educational goverance - a finish case". International journal of educational management،Vol. 27، Issue. 4، 2013، p. 403

34-Jem Bendell\& Richard Little : "Seeking sustainability leadership", The journal of corporate citizenship , No. 60, 2015, p. 16

35-TinnaLyee Evans :" Leadership without Domination?: Toward Restoring the Human and Natural World"، Journal of sustainability education، Vol. 2، March 2011، p. 13

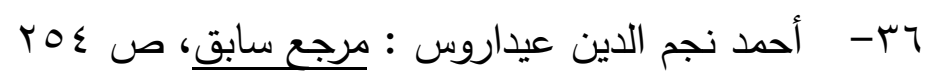

37-Rosland Ann Hardie : Op.Cit, p.67

38-Jack Mccann\& Matthew Sweet : Op.Cit ,p.375

39-Emma Savage, et. Al : "Experiential Learning for Sustainability Leadership ", Journal of sustainability in Higher Education, Vol.16, Iss5 , 2015, p. 695

40-Laura Gerard \&Et.al :" Conceptualizing sustainable leadership "،Industrial and commercial training journal، Vol. 49 ، 2017 ، p.118

41-John W. Cook : Sustainable school leadership : The teachers perspectives , International journal of educational leadership preparation, Vol. 9, No.1, March 2014, p.p 12,13

42-Hairuddin Harun \& SitiKhadijah Mat Man: " leadership development and sustainable leadership among Tvet student " ‘. Journal of management policies and practices، Vol.2, No. 2, June 2014 , p. 33.

43-SooksanKantabutra\&MolraudeeSaratun: "Sustainable leadership: honeybee practices at Thailand's oldest university"..International Journal of Educational Management، Vol. 27، Issue: 4، 2013,p. 632 44-John W. Cook : Op.Cit., p.4

45-SuparakSuriyankiethaew\& Gayle C. Avery : "Employee satisfaction and sustainable leadership practices in Thai SME"،Journal of global responsibility،Vol. 5، Issue. 1، 2014, p. 161. 
46-Stephen Jacobson :" Leadership effects on student achievement and sustrained school success".International journal of educational management، Vol. 25، Issue. 1، 2011, p. 34

47-Heather L. Burns : " Learning sustainability leadership : An action researchstudy of a graduate leadership course " . International Journal for the scholarship of teaching and learning، Vol.10 ‘No. 2، 2016, p.5

48-SooksanKantabutra\&MolraudeeSaratun : Op.Cit., p. 361

49-SooksanKantabutra\&MolraudeeSaratun : Op.Cit., p. 362

50-James Muhla\& Maureen Gitan : sustainable student leadership in Africa today $67^{\text {th }}$ Annual conference * The ethics of sustainable development in higher education Strathmore university، $28^{\text {th }}-29^{\text {th }}$ 。 October 2010,p. 5

51-Andy Hargreaves : Op.Cit., p.225

52-Hairuddin Harun \& SitiKhadijah Mat Man : Op.Cit, p. 36

53-Jennifer Foster : Schooling for sustainable development in Canada and United States ، library of congress ، New York ، Vol. 4 ،2013, p.p 270,271

54-Andy Hargreaves \& Dean Finik : Sustainable leadership, Jossy-Bass, 989 Market st.,San francisco , 2006,p.6

55-Steve Lambert :" The perception and implements of sustainable strategies in further education colleges "‘Journal of leadership education ، Vol. 11، 2012, p. 103

56-Andy Hargreaves \& Dean Finik: Op.Cit., p.6

57-Lucia Varra\&MarziaTimolo: Sustainable leadership practices according to international standerds of corporate social responsibility ‘Electoronic Journal of management، No. 3 ، 2017, p. 5

58-Hairuddin Harun \& SitiKhadijah Mat Man : Op.Cit., p.p 35,36

59-Andy Hargreaves \& Dean Finik : Op.Cit., p.6

• - عبد الكريم محمد الدرايسة و رامي إبراهيم الثقران : "أهمية التثريعات التربوية ودورها

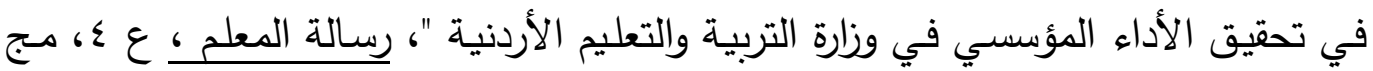
. T 
61-Iqbal M. \& Yalmaz A. :Analysis of workplace stress and organizational performance in humane resource management, A case study of air traffic controllers of Pakistan, International journal of management and sustainability, Vol. 3 , No. 6, 2014, p. 326

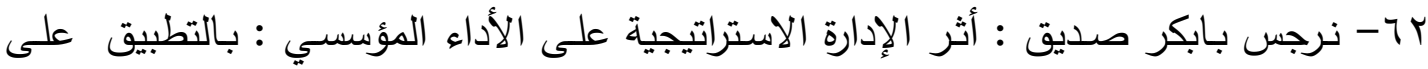

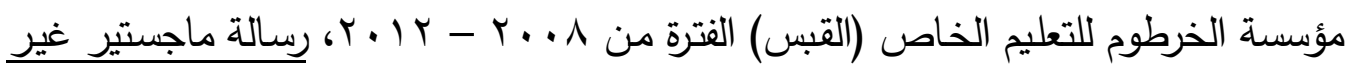

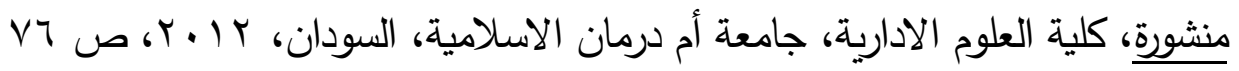

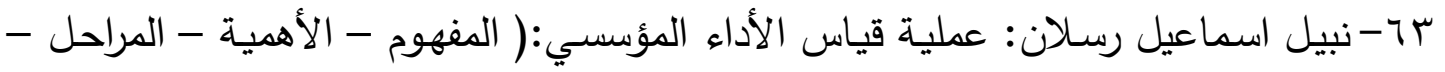

الأنشطة - الصعوبات)، أعمال ندوات: الأساليب الحديثة في قياس الأداء الحكومي خلال

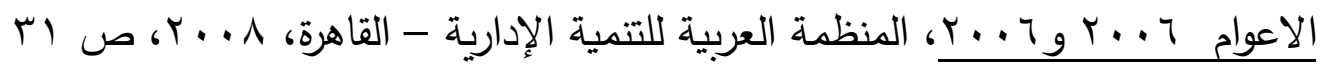

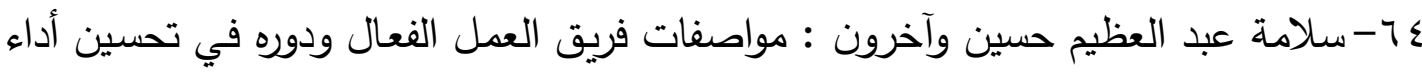

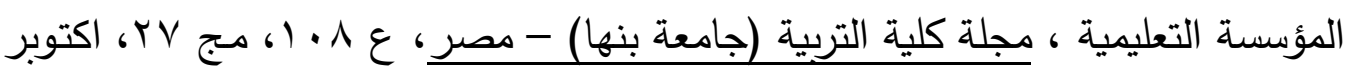

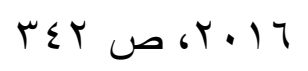

01 - أحمد جاد حسين : "تطوير الاداء المؤسسي بجامعة جنوب الوادي في ضوء معايير

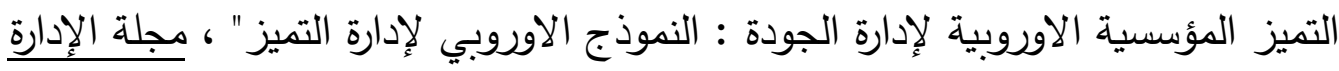

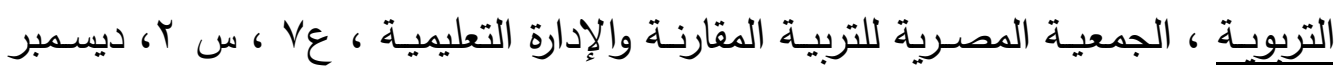

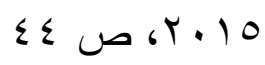

66-Sunday I. \& Caroline O.: Influence of organizational culture on performance management, Akwa Ibom state, Nigeria, International journal of Humanities and social science, Vol. 4, No.6 ,April 2014,p. 301

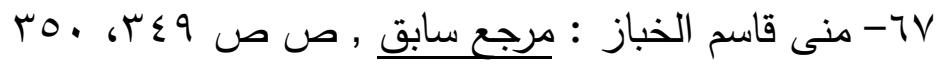

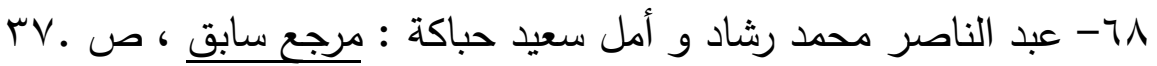

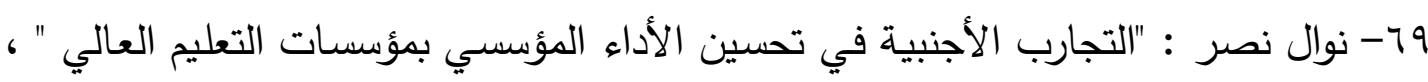

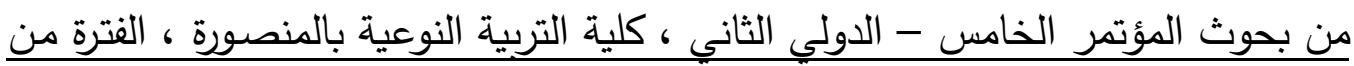

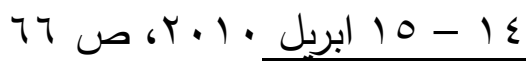

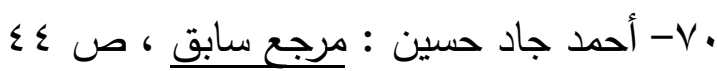

71-Jackson B. Et.al: Employee motivation, Job Satisfaction and organizational performance in Uganda 's oil sub - sector, Global advanced research Journal of management and business studies, Vol. 3 , No. 7, July 2014, p. 316 


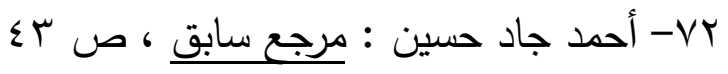

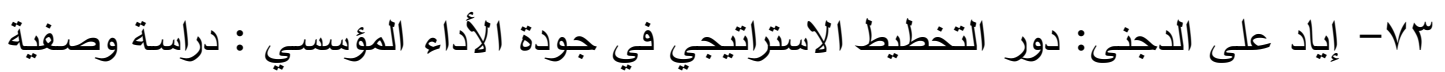
تحليلية للجامعات النظامية الفلسطينية ، رسالة دكتوراه غير منشورة ، كلية التربية، جامعة

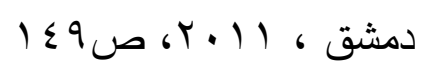

ع V- خالد محمود عبد الوهاب : " أبعاد السلوك الحكيم وعلاقتها بكفاءة الأداء الإداري " ،

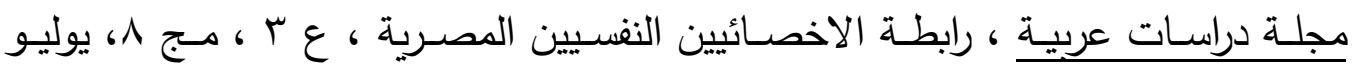

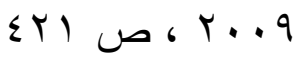

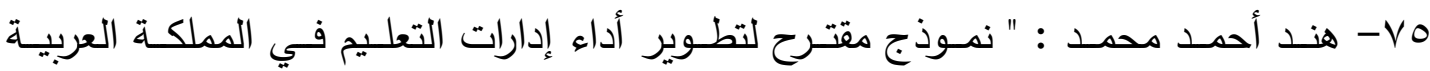

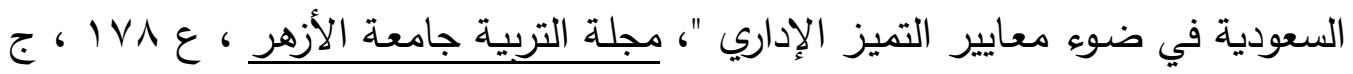

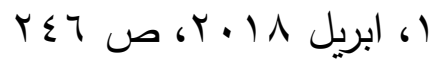

1VY- مشعل خالد اسماعيل : " تصور مقترح لتطوير الأداء الإداري في المؤسسات التعليمية في

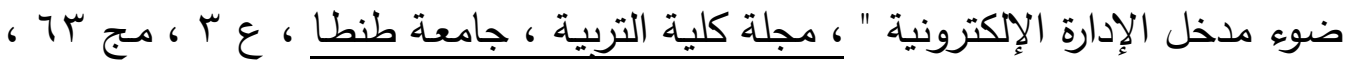

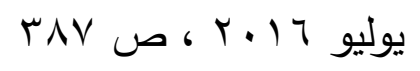

PV - رامي موسى الهبيل : دور المساءلة الإداريـة لدى قسم الرقابة الداخلية وعلاقته بتحسين

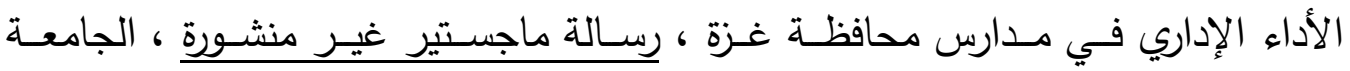

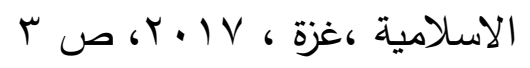

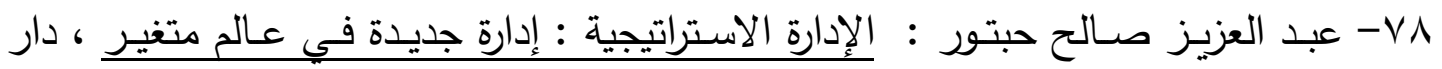

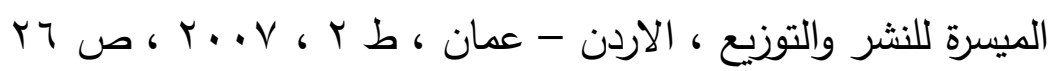

79- Ehtesham ul Mujeeb \& Muhammad Shakil Ahmad : " Impact of organizational culture on performance management practices on Pakistan ", International management review, Vol. 7, No. 2, 2011, p. 53

80- Fakhar Shahzad et.al.: " Impact of organizational culture on organizational performance : An over view ", Interdisciplinary journal of contemporary research business, Vol. 3 ,No. 9, January 2012, p. 53

ای- صـفاء رافـع محمــ : درجـة الثـراكة المؤسسـية بـين إدارات المـدارس الثانويـة وإدارات

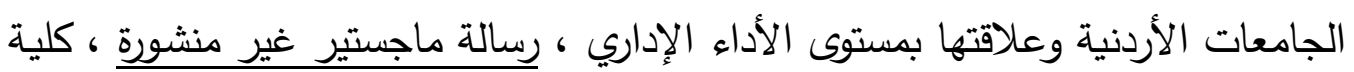

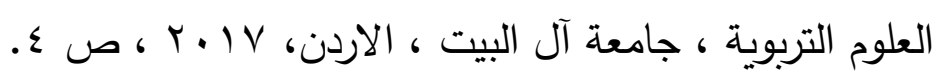

